\title{
An analytical method to assess the structural responses of ship side structures by raked bow under oblique collision scenarios Zeping Wang ${ }^{1}$, Kun $\mathrm{Liu}^{2}$, Gang Chen ${ }^{1,3}$, Zhiqiang $\mathrm{Hu}^{4,5}$
}

\author{
${ }^{1}$ State key Laboratory of Ocean Engineering, Shanghai Jiao Tong University, Shanghai, China; \\ ${ }^{2}$ Jiangsu University of Science and Technology, Zhenjiang, Jiangsu, China; \\ ${ }^{3}$ Marine Design and Research Institute of China, Shanghai, China; \\ ${ }^{4}$ School of Engineering, Newcastle University, Newcastle upon Tyne, UK; \\ ${ }^{5}$ College of Shipbuilding Engineering, Harbin Engineering University, Harbin, China
}

Abstract: With the development of the shipping industry, the number of ships at sea has increased significantly. According to the statistical data, oblique ship collisions are much more frequently happened than that of head-on ship collisions. However, there are less available researches on oblique ship collisions than those of head-on ship collisions. The responses of hull structure during oblique collision scenarios are different from those in head-on collision scenarios, and might have severer and wider structural damages, which demonstrate the significance of research on oblique collision scenarios and structural damage. In this paper, the oblique collision scenarios are firstly investigated through numerical simulations. Finite element software LS_DYNA is used for the numerical simulations. Six typical oblique collision scenarios are defined, on purpose of finding the main deformation characteristics of the struck ship. Two basic assumptions were made accordingly. Then, a simplified analytical method is proposed to predict the structural response of ship side structures by raked bow under oblique collision scenarios. The new analytical method includes the deformation mechanism of the side plating, the web girder and the transverse frame. The resistance and energy dissipation of these components are used in an integrated way to evaluate the overall crashworthiness of the side structure of the struck ship. The numerical simulation results match well with the results of analytical calculations, which validates the accuracy of the proposed analytical method. The proposed analytical method can provide an effective way to evaluate the structural crashworthiness of ship side structures in oblique collision scenarios during the structural design stage.

Keywords: Oblique ship collision, Raked bow, Crashworthiness, Analytical method, Numerical simulation

\begin{tabular}{|ll|}
\hline Nomenclature \\
$F$ & the plastic force \\
$E_{m}^{\&}$ & the loading rate \\
$N_{b}$ & the membrane energy dissipation rate \\
$\&_{a v g}$ & the unit plastic membrane force \\
$M_{0}$ & the unit plastic bending moment \\
\hline
\end{tabular}




\begin{tabular}{|c|c|}
\hline$\beta_{i}$ & the curvature rate \\
\hline$l_{i}$ & the length of hinge number $i$ \\
\hline$\sigma_{0}$ & the flow stress \\
\hline$t$ & the thickness of the plate \\
\hline$L$ & height of the deformed side plating \\
\hline$L_{1}$ & length of the left side of the deformed side plating \\
\hline$L_{2}$ & length of the right side of the deformed side plating \\
\hline$\alpha_{1}$ & the instantaneous rotation angle of the left side in the longitudinal direction \\
\hline$\alpha_{2}$ & the instantaneous rotation angle of the right side in the longitudinal direction \\
\hline$\beta$ & the collision angle between the striking ship and the struck ship \\
\hline$\theta$ & the rotation angle of the side plating in the vertical direction \\
\hline$\Delta$ & the deflection of the side plating \\
\hline$F_{V}$ & the vertical force \\
\hline$F_{\text {sideplate }}$ & the collision force of the side plating \\
\hline$l$ & the length of the plate strip \\
\hline$\varepsilon_{1}$ & the strain of the left part of the deformed plate \\
\hline \&\& & the strain rate of the left part of the deformed plate \\
\hline$\varepsilon_{2}$ & the strain of the right part of the deformed plate \\
\hline$\& \&$ & the strain rate of the right part of the deformed plate \\
\hline \& & the angular bending rate of the left part in the longitudinal direction \\
\hline$\&$ & the angular bending rate of the right part in the longitudinal direction \\
\hline$S_{1}$ & the area of the left part of the deformed plate \\
\hline$S_{2}$ & the area of the right part of the deformed plate \\
\hline$N_{0 \_ \text {sideplate }}$ & the unit plastic membrane force of the plate trip per length \\
\hline$t_{\text {sideplate }}$ & the thickness of the side plating \\
\hline$e_{b 1}^{\&}$ & $\begin{array}{l}\text { the energy dissipation rate of the bending deformation in the longitudinal } \\
\text { direction }\end{array}$ \\
\hline$E_{b 2}^{\&}$ & the energy dissipation rate of the bending deformation in the vertical direction \\
\hline$\S$ & the angular bending rate of the deformed plate in the vertical direction \\
\hline$F_{V_{-} \text {sideplate }}$ & the vertical force of the side plating \\
\hline$F_{T_{-} \text {sideplate }}$ & the tangential force of the side plating \\
\hline$F_{\text {sideplate }}$ & the collision force of the side plating \\
\hline$F_{S_{-} \text {sideplate }}$ & the frictional force between the raked bow and the side plating \\
\hline$E_{f}$ & the energy dissipation due to friction \\
\hline$b_{1}$ & length of the left side of the web girder \\
\hline$b_{2}$ & length of the right side of the web girder \\
\hline$H$ & the crushing height \\
\hline$H$ & the crushing distance in the oblique collision direction \\
\hline$E_{b}$ & the bending energy dissipation \\
\hline$\dot{\alpha}$ & the angular bending rate \\
\hline
\end{tabular}




\begin{tabular}{|c|c|}
\hline$\delta$ & the indentation \\
\hline$\alpha$ & the rotation angle \\
\hline$\dot{\delta}$ & the impact velocity \\
\hline$\varepsilon_{O A}$ & the strain of the fibre OA \\
\hline$\& \&_{A}$ & the strain rate of the fibre $\mathrm{OA}$ \\
\hline$\& \&_{B}$ & the strain rate of plastic hinge line $\mathrm{OB}$ \\
\hline$\&$ \& & the strain rate of plastic hinge line $\mathrm{OC}$ \\
\hline$\stackrel{\&}{a v g}$ & the average strain rate along the length direction \\
\hline$E_{m}$ & the membrane energy dissipation \\
\hline$\delta$ & the raked bow displacement \\
\hline$F_{\text {girder }}$ & the instantaneous resistance of the web girder \\
\hline$F_{m_{-} \text {first }}$ & the average resistance of the web girder during the formation of the first fold \\
\hline$F_{\text {membrane }}$ & $\begin{array}{l}\text { the membrane instantaneous resistance of the web girder during the formation } \\
\text { of the second fold }\end{array}$ \\
\hline$E_{2 b}$ & the bending energy dissipation during the formation of the second fold \\
\hline$F_{\text {bending }}$ & the resistance of the second fold due to bending deformation \\
\hline$F_{\text {flange }}$ & the resistance of the flange plate \\
\hline$F_{\text {total }}$ & the total instantaneous resistance of the web girder with flange plate \\
\hline$u$ & the horizontal displacement in the edge of the transverse frame \\
\hline$h$ & half of the vertical crushing distance \\
\hline$\theta_{1}$ & half of the crushing wave angle \\
\hline$d$ & the length of a linear load \\
\hline$E_{t}$ & the total energy dissipation of the transverse frame \\
\hline$F_{T_{-} \text {frame }}$ & the tangential force of the transverse frame \\
\hline$F_{V_{-} \text {frame }}$ & the vertical force of the transverse frame \\
\hline
\end{tabular}

\section{Introduction}

With the development of maritime trade, ocean routes are becoming crowded. However, although many advanced equipment and technologies have been applied to assist ship navigation, ship collisions are still inevitably happening every year. Ship collisions lead to serious consequences, such as hull damage, casualties and severe environmental pollution. One of the most serious oil tanker collision accidents in history was the collision between the Atlantic Empress and the Aegean Captain, the crude oil spilled into the Caribbean Sea, and the Atlantic Empress tanker eventually sank to the bottom of the sea. The occurrence of these accidents has aroused widespread concern in the international community. Therefore, to improve the safety of marine navigation, new regulations have been proposed. The famous regulations are the Safety of Life at Sea (SOLAS) Convention and the Oil Pollution Act 90 (OPA90). The International Maritime Organization (IMO) mandates the use of double-hulls for tankers. In addition, some new design methods for improving ship safety have also been proposed, such as the accidental limit state (ALS) design method.

According to statistical data, the striking angles of ship collisions are normally distributed $^{1}$ and oblique collision scenarios are more frequent. A ship collision is a 
dynamic nonlinear process, and a large amount of kinetic energy is absorbed by the hull structure within a short period of time, which may cause the hull structure to exceed the elastic deformation and to enter into the plastic deformation, or possibly tear and rupture. Many scholars have studied the deformation mechanisms of hull structures during ship collisions. The main research methods include empirical formula methods, experimental methods, finite element numerical simulation methods and simplified analytical methods.

It is commonly agreed that the ship collision research was initiated by Minorsky ${ }^{2}$. Based on the statistical analysis of ship collisions, Minorsky established a linear relationship between the structural damage volume and the collision energy dissipation, and derived an empirical formula. Later, Woisin ${ }^{3}$, Vaughan ${ }^{4}$, Pedersen and Zhang ${ }^{5}$ further modified Minorsky's empirical formula to provide better accuracy. By comparing with the experimental results from the public literature, Zhang and Pedersen ${ }^{6}$ re-examine the effectiveness and accuracy of this method in ship collision damage analysis.

Experimental methods are one of the most convincing methods for studying ship collision problems. Since the early 1960 s, scholars have carried out many ship collision and grounding tests. Pedersen et al. ${ }^{7}$ and Akita et al. ${ }^{8}$ conducted experiments in order to design the ship structure to have sufficient strength to resist impact. In addition, Amdahl $^{9}$, Paik ${ }^{10}$, and Wang et al. ${ }^{11}$ conducted model tests to study the deformation of the hull structure during collision and grounding processes. Tabri et al. ${ }^{12}$ carried out full- scale experiments to verify the proposed theoretical model for predicting the shipship collision. A series of experiments using scale models were conducted by Endo et al. ${ }^{13}$ to study the collision mechanism of the bulbous bow. Experiments of a tanker side panel impacted by a knife edge indenter were carried out by Villavicencio et al. ${ }^{14}$ to research the energy absorbing mechanisms. Liu and Soares ${ }^{15}$ conducted experiments to study the effect of strain rate on dynamic response of laterally impacted steel plate. Calle et al. ${ }^{16}$ carried out scaled experiments to validate the finite element analysis and discussed the effects of different numerical and experimental factors on impact tests of marine structures. Miniature ship grounding tests were conducted by Calle et al. ${ }^{17}$ to investigate the influence of the element size and strain rate on the fracture of steel plate when analysis by finite element method. Experimental investigations need a large amount of capital for real ship tests or large-scale model tests. For a small-scale model test, the nonlinear behaviour in ship collision and grounding process will bring the scale effect, and the test results may not be accurately converted to a real ship scale, thereby resulting in some unexpected errors.

With the rapid development of computing technology, finite element numerical simulation method has been becoming a powerful tool for ship collision research. Haris and Amdahl ${ }^{18}$ simulated several ship collision scenarios with the finite element software LS-DYNA and validated the proposed analytical calculation method. Yamada and Endo ${ }^{19}$ investigated the crashworthiness of hull structures in ship oblique collision scenarios. Yu et al. ${ }^{20}$ and $\mathrm{Hu}$ et al. ${ }^{21}$ performed a series of numerical simulations of ship grounding scenarios and validated the analytical method proposed by Hong and Amdahl $^{22}$. Ringsberg and Hogström ${ }^{23}$ used the finite element method to assess the crashworthiness of the new type of side structures. Ringsberg et al. ${ }^{24}$ conducted a 
benchmark study on nonlinear finite element numerical simulation of an experiment of a rigid indenter impact a ship side structure. Kitamura ${ }^{25}$ used the finite element method to analyze the structural performance of ships in collision scenarios. Numerical analysis was carried out by Alsos et al. ${ }^{26}$ to simulate the experiment of stiffened plates subjected to collision actions. Ehlers et al. ${ }^{27}$ implement the material relationships into the finite element model to investigate the collision resistance of the X-core structure. The ductile crack propagation of large-scale shell structures was simulated by Simonsen and Törnqvist ${ }^{28}$. Liu et al. ${ }^{29}$ developed a numerical simulation method for structural impact considering the influence of strain rate. Liu and Soares ${ }^{15}$ also studied the influence of strain rate on the dynamic response of laterally impacted steel plate through numerical simulations. Zhu et al. ${ }^{30}$ used numerical simulation and experiment methods to analyze the interaction between the structural response of an elastic-plastic struck plate of a fluid tank subjected to impact and the effect on the fluid motion. However, due to the large amount of modelling work and long calculation time, numerical simulation methods still needs further improvements.

Compared to the previous three methods, simplified analytical methods have the advantages of high efficiency and reasonable accuracy. Simplified analytical methods mostly use the upper bound theorem to analyse the plastic mechanism of structures. Alexander ${ }^{31}$ made a milestone work by applying the simplified analytical method for the response analysis of thin-walled structures. During recent decades, many scholars proposed their analytical methods and programmes, for instance, Wang ${ }^{32}$ proposed many analytical formulas for the deformation mechanism analysis of ship structures in ship collision and grounding scenarios. Simonsen ${ }^{33}$ and Zhang $^{34}$ proposed analytical formulas for calculating the deformation resistance of ship bottom plate. Afterwards, Hong and Amdahl ${ }^{35}$, Liu and Soares ${ }^{36}$ derived formulas for calculating the crushing resistance of web girders by using the elastic-plastic method. Yu et al. ${ }^{37}$ also used elastic-plastic method to analyse the performance of stiffeners on web girders in a shoal grounding scenario. An elastic-plastic method is proposed to evaluate the plastic deformation and failure of ship structures subjected to collision by $\mathrm{Liu}^{38}$. Nevertheless, the existing analytical methods mostly apply for head-on collision scenarios, which have been taken for granted as the most critical scenario. In real collision scenarios, oblique collision scenarios account for most number but the related analytical researches are not adequate.

According to the statistical data, oblique ship collisions are much more frequently happened than that of head-on ship collisions. Oblique collision scenarios will cause larger scope of structural components into deformation and failure that may lead to severer structural damage in ship length but not in penetration, which is different from previous studies. However, there are less available researches on simplified analytical methods of oblique ship collisions than those of head-on ship collisions. This paper carries out a study on oblique ship collision scenarios and structural responses. In this paper, the oblique collision scenarios are firstly investigated through numerical simulations, on purpose of finding the simplification basis and assumptions for analytical deductions. Six oblique collision scenarios are defined, and the nonlinear finite element software LS_DYNA is used for the numerical simulations. The 
deformation mechanism of the side structure of a ship subjected to a raked bow oblique collision is investigated through simplified analysis method and the analytical formulae are proposed to predict the crashworthiness of the ship side structure in raked bow oblique collision scenarios. The new analytical formulae include the deformation mechanisms of the outer shell plating, the web girder, the transverse frame, and the resistance and energy dissipation formulas are proposed. Then, the overall crashworthiness of the side structure can be evaluated in an integrated way. Finally, the numerical simulation results are compared with the analytical calculation results, and the comparison results match well, which illustrates the accuracy of the proposed analytical method. The proposed analytical method can be used for the crashworthiness evaluation of the side structure in an effective way during the structural design stage.

\section{Numerical simulations}

In order to find the main deformation characteristics of the oblique collision scenarios and provide a basis for the derivation of the analytical formulae, firstly, numerical simulations are carried out to simulate the oblique collision process by using the finite element software LS_DYNA.

\subsection{Finite element model}

In the numerical simulation, a cargo ship with raked bow is chosen as the striking ship, and a double-hull tanker is selected as the struck ship. The main details of the struck tanker and the striking ship are listed in Tables 1 and 2, respectively. And the finite element models of the side structure of the struck ship and the striking ship are shown in Figure 1 and Figure 2. Four-node quadrilateral Belytschko-Tsay (ELFORM2) element is used for element type of the struck ship, and the material model of the struck ship selected from the library of LS_DYNA is "Mat.003-Plastic Kinematic". The material of the striking ship is defined as rigid, "Mat.020-Rigid" in the library of LS_DYNA is used for the material model of the striking ship. The material yielding stress of the deck is $355 \mathrm{MPa}$, and the material yielding stress of the other side structural components is $235 \mathrm{MPa}$. In order to obtain a reasonable simulation time, capture the main deformation characteristics and ensure the accuracy of numerical simulation, convergence study was carried out and the results of the convergence study are presented in Section 2.3. Thus, the mesh size of the side structure selected in numerical simulation is $200 \mathrm{~mm}$. The rupture criterion used in numerical simulation is the critical equivalent plastic strain method, and the failure strain is defined as 0.35 . Besides, the friction coefficient is set to be $0.3^{19}$, and the striking velocity is set to be $3 \mathrm{~m} / \mathrm{s}$. The side structure is restricted by fixing the six degrees of freedom at both ends of the finite element model in the longitudinal direction, the six degrees of freedom of the striking ship is not restricted to ensure that the actual motion of the striking ship can be simulated. The contact between the striking ship and the struck ship is an automatic surface-to-surface contact in LS_DYNA, whereas the contact of the side structure on the struck tanker is an automatic single surface in LS_DYNA. 


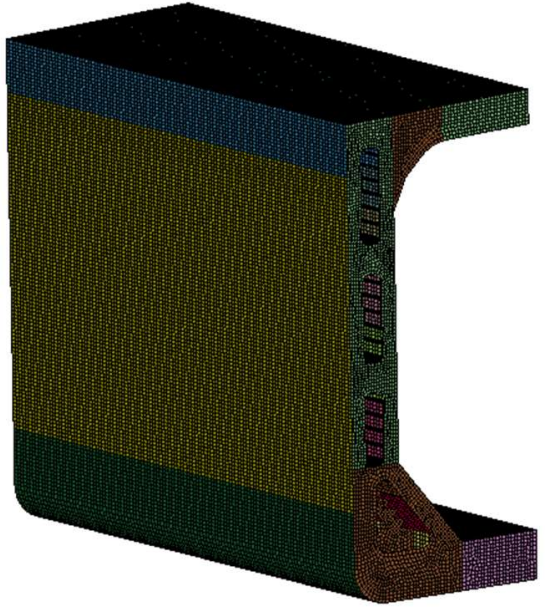

(a)

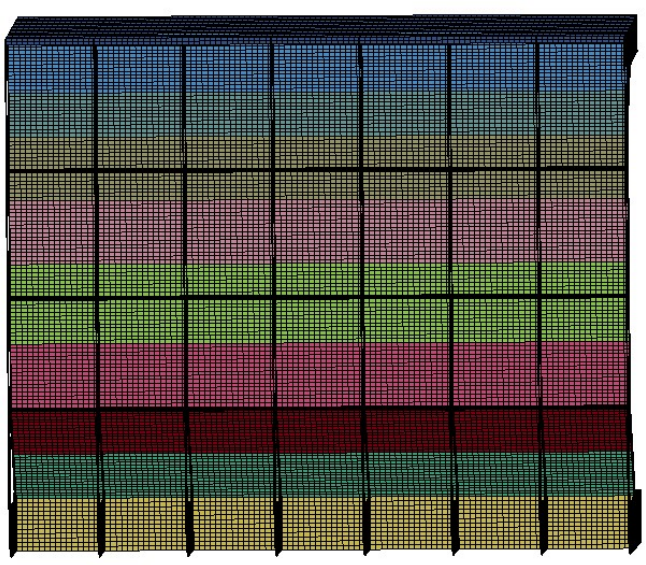

(b)

Figure 1. Finite element model of the side structure of the tanker: (a) the FE model, (b) the model without the outer plating and stiffeners.

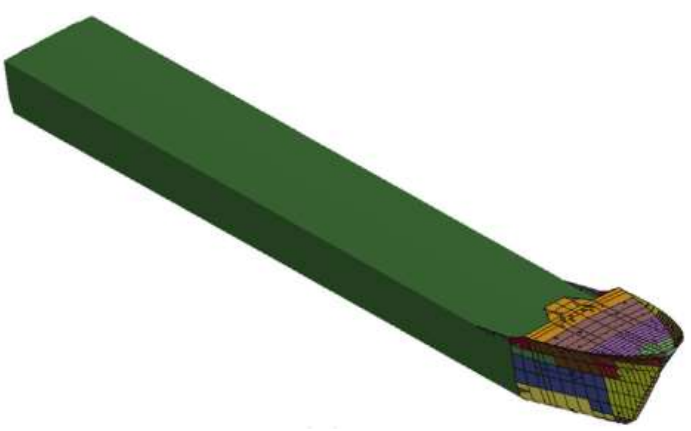

(a)

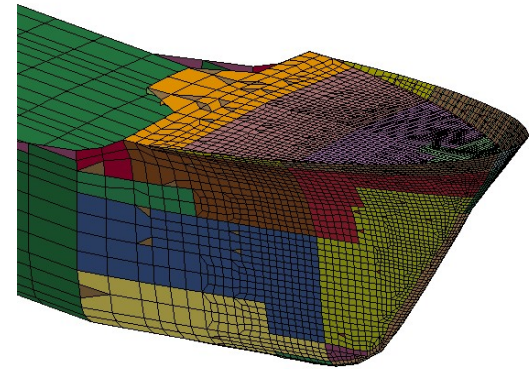

(b)

Figure 2. Finite element model of the cargo ship: (a) the FE model, (b) the model of the raked bow (locally zoomed).

Table 1. Main scantlings and structural details of the struck tanker.

\begin{tabular}{lc}
\hline Item & Value \\
\hline Length & $288.0 \mathrm{~m}$ \\
Breadth & $65.0 \mathrm{~m}$ \\
Depth & $29.4 \mathrm{~m}$ \\
Design draught & $22.0 \mathrm{~m}$ \\
Length of one compartment & $35.0 \mathrm{~m}$ \\
Spacing of double side plating & $3.38 \mathrm{~m}$ \\
Spacing between longitudinal girders & $7.2 \mathrm{~m}$ \\
Spacing between transverse web frames & $5.0 \mathrm{~m}$ \\
Spacing between stiffeners & $0.9 \mathrm{~m}$ \\
The thickness of outer shell plating & $21 \mathrm{~mm}$ \\
The thickness of inner shell plating & $15 \mathrm{~mm}$ \\
The thickness of web girder & $12 \mathrm{~mm}$ \\
The thickness of transverse web frame & $14 \mathrm{~mm}$ \\
The thickness of stiffener & $13 \mathrm{~mm}$ \\
\hline
\end{tabular}

Table 2. Main scantlings of the striking cargo ship.

Item Value




\begin{tabular}{lc} 
Length & $107.0 \mathrm{~m}$ \\
Breadth & $15.0 \mathrm{~m}$ \\
Depth & $7.49 \mathrm{~m}$ \\
Design draught & $6.4 \mathrm{~m}$ \\
\hline
\end{tabular}

\subsection{Collision scenario definition}

Figure 3 is a schematic of an oblique collision, and the oblique collision angle $\beta$ is defined. Three collision positions are defined and shown in Figure 4, and Table 3 lists six oblique collision scenario cases, and they are also shown in Figure 5. In case 1-3, the impact position is position 1 ; in case $4-6$, the impact position is position 2 , and as the collision progresses, the striking ship will pass through position 3 .

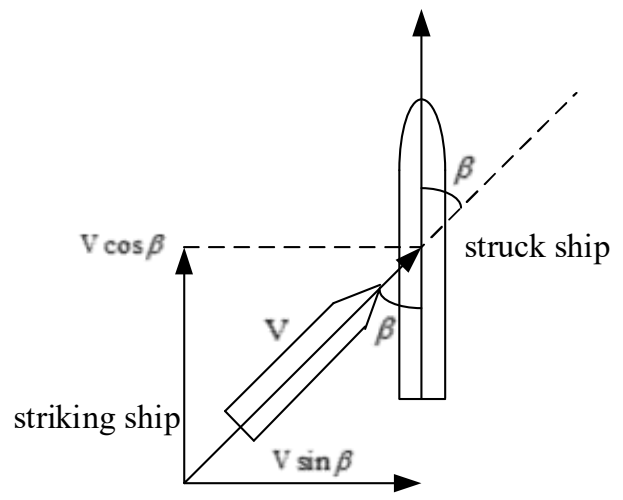

Figure 3. Definition of the oblique collision angle $\beta$.

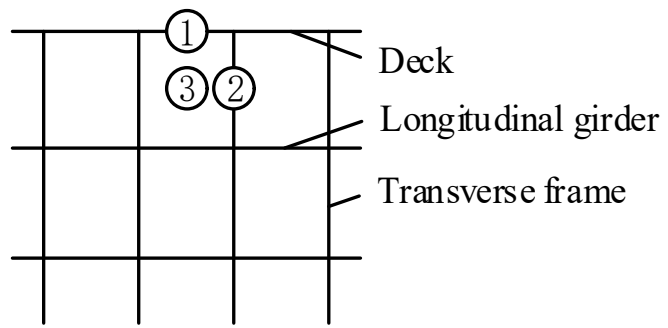

Figure 4. Three typical collision positions.

Table 3. Typical collision positions in different case definitions.

Case Collision angle Impact starting position and passing position

\begin{tabular}{lll}
\hline Case 1 & $30^{\circ}$ & Position 1 \\
Case 2 & $45^{\circ}$ & Position 1 \\
Case 3 & $60^{\circ}$ & Position 1 \\
Case 4 & $30^{\circ}$ & Positions 2 and 3 \\
Case 5 & $45^{\circ}$ & Positions 2 and 3 \\
Case 6 & $60^{\circ}$ & Positions 2 and 3 \\
\hline
\end{tabular}




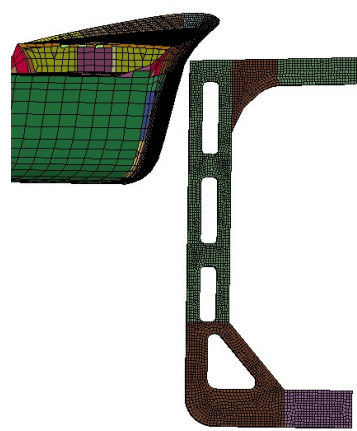

(a) Case 1: $\beta=30^{\circ}$

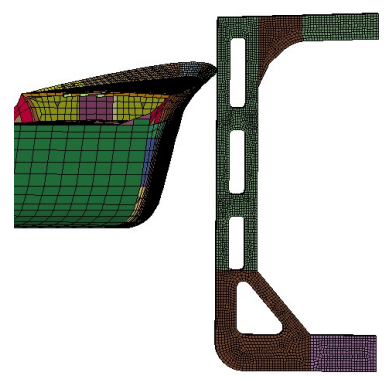

(d) Case 4: $\beta=30^{\circ}$

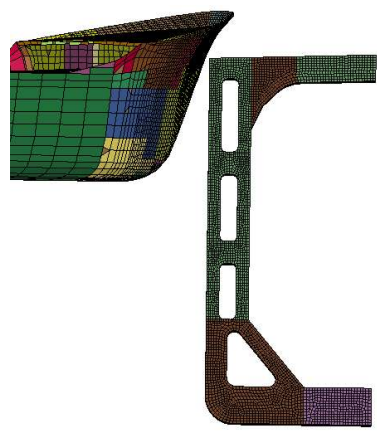

(b) Case 2: $\beta=45^{\circ}$

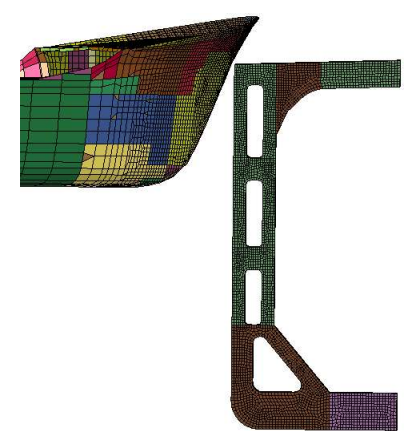

(c) Case 3: $\beta=60^{\circ}$

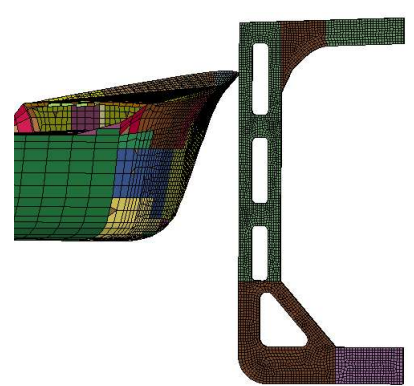

(e) Case 5: $\beta=45^{\circ}$

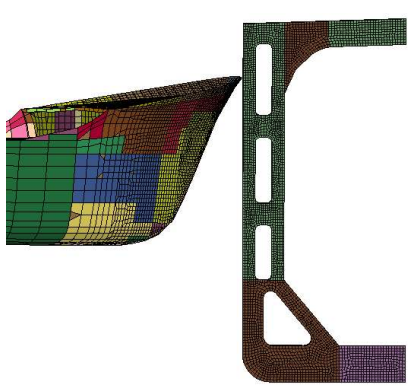

(f) Case 6: $\beta=60^{\circ}$

Figure 5. Six oblique collision cases.

\subsection{Convergence study}

In order to capture the main deformation modes, ensure the accuracy of numerical simulation and obtain a reasonable simulation time, convergence study under different oblique angles was carried out. The results show that the simulation results of the side structure with the mesh size of $100 \mathrm{~mm}, 200 \mathrm{~mm}$ and $300 \mathrm{~mm}$ are similar, which is shown in Figure 6. According to the research of Zhang et al. ${ }^{39}$, the failure strain is highly affected by the mesh size, with the increase of the mesh size, the failure strain decreases, so the collision force of $100 \mathrm{~mm}$ mesh is slightly larger than that of $200 \mathrm{~mm}$ and 300 $\mathrm{mm}$ mesh. Therefore, considering the accuracy of numerical simulation and the reasonable simulation time, mesh size of the side structure selected in numerical simulation is $200 \mathrm{~mm}$ in this study.

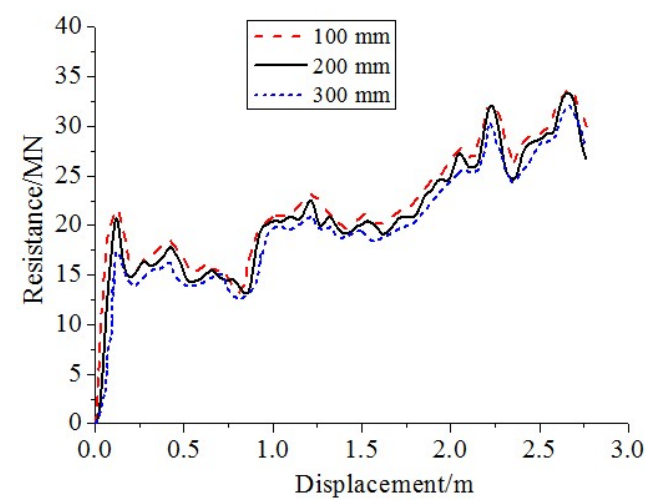

(a) The convergence study of case $1\left(\beta=30^{\circ}\right)$.

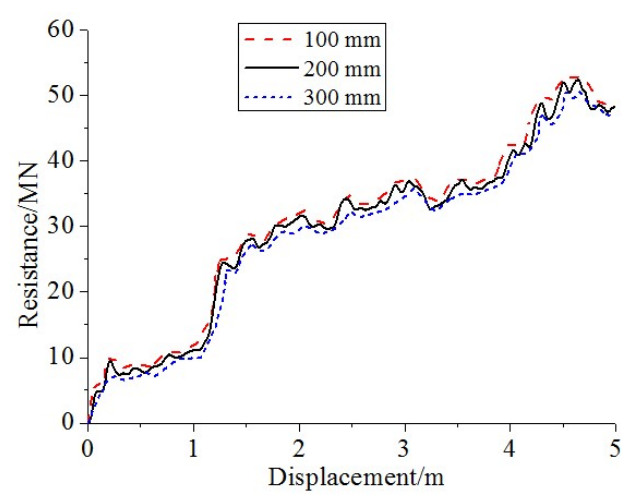

(b) The convergence study of case $2\left(\beta=45^{\circ}\right)$. 


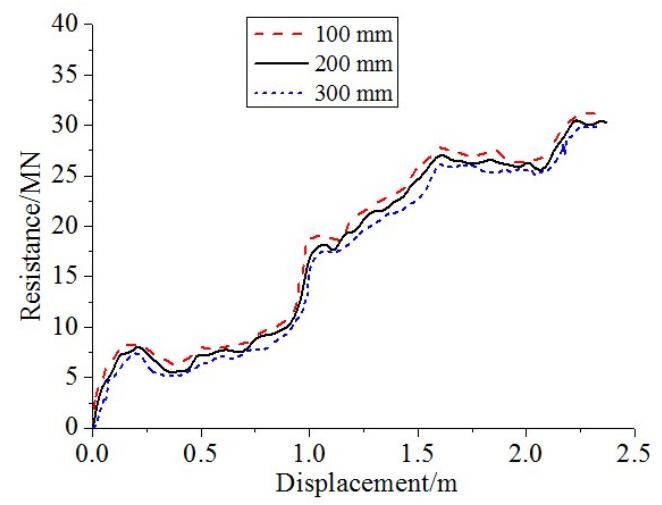

(c) The convergence study of case $3\left(\beta=60^{\circ}\right)$.

Figure 6. The convergence study.

\subsection{The characteristics of oblique collision and assumptions}

In the numerical simulation, a 50000 DWT cargo ship is chosen as the striking ship, the motion of the striking ship is not restricted to ensure that the actual track of the striking ship can be simulated. The damage of the struck ship's side structure and motion tracks of the striking ship are related to the collision angle and the mass of the striking ship. Through the numerical simulation results, we find that the moving direction of the striking bow changes little and basically keeps the original striking direction. This oblique collision scenario character owes to the side structures' restriction effect on the striking bow with the deformation of side shell, and it suppresses the sliding motion of the striking bow quite a lot. The finding of this character helps us to make important assumptions for further structural deformation analytical analysis.

Therefore, based on the numerical simulation results, two assumptions can be made as below, for the analytical analysis in Section 3.

1) In the analytical analysis of internal mechanism of the oblique collision scenarios, it is assumed that the striking bow does not change its direction during the collision process. Therefore, the total collision force is defined as the same direction as that of the original striking direction.

2) In order to simplify the analytical process, as the indentation of the striking ship is not large enough to cause the rupture of the outer shell plating in case 1-6, the rupture of the outer shell plating of the struck ship is not taken into consideration in this study.

\section{Simplified analytical method}

The crashworthiness of a struck ship can be promptly evaluated by using a simplified analytical analysis method. It is assumed that there is no interactions between structural components of the struck ship. In addition, the resistance of the side structure is summed by the resistances of all the individual structural components, and the overall crashworthiness of the ship side structure can be obtained.

\subsection{Fundamental theory and basic assumptions}

Jones ${ }^{40}$ summarized the simplified analytical method. The upper bound theorem of plastic mechanics theory was described concisely by Søreide ${ }^{41}$, which is used to obtain 
the resistance of the plating structure under the impact of a raked bow, and the instantaneous resistance can be derived by:

$$
F \cdot \&=E_{m}^{\&}+E_{b}^{\&} 41
$$

where, $F$ is the plastic force, $\mathbb{E}^{\&}$ is the loading rate, $E_{m}^{\&}$ is the membrane energy dissipation rate and $E_{b}^{\&}$ is the bending energy dissipation rate,

$$
\begin{gathered}
E_{m}^{\&}=\int_{S} N_{0} \underset{a v g}{\&} d S^{41} \\
E_{b}^{\&}=\sum_{i=1}^{n} M_{0} \beta_{i}^{\&} l_{i}^{41}
\end{gathered}
$$

where, $N_{0}$ is the unit plastic membrane force, $\&_{a v g} i s$ the average strain rate, $M_{0}$ is the unit plastic bending moment, $\beta_{i}^{\&}$ is the curvature rate and $l_{i}$ is the length of hinge number $i$,

$$
\begin{aligned}
& M_{0}=\frac{\sigma_{0} t^{2}}{4} \\
& N_{0}=\sigma_{0} t
\end{aligned}
$$

where, $\sigma_{0}$ is the flow stress and $t$ is the thickness of the plate.

When the side structure of the struck ship is subjected to an oblique collision, the outer shell plating, the longitudinal girder, the deck plating and the transverse frame as the main components to resist the collision force, the deformation mechanism of the deck plating is similar to that of the longitudinal girder. Therefore, the deformation mechanisms of the outer shell plating, the longitudinal girder and the transverse frame subjected to oblique collision are investigated in the following sections.

\subsection{Deformation mechanism of the outer shell plating in an oblique collision scenario}

The shape of the striking bow is related to the deformation pattern of the outer shell plating. Based on the deformation pattern of the outer shell plating in numerical simulation, a theoretical deformation model of the outer shell plating in a raked bow oblique collision scenario is proposed, and the theoretical deformation model of the outer shell plating after collision is shown in Figure 7. In this paper, as the indentation of the striking ship is not large, so the rupture of outer shell is not taken into consideration.

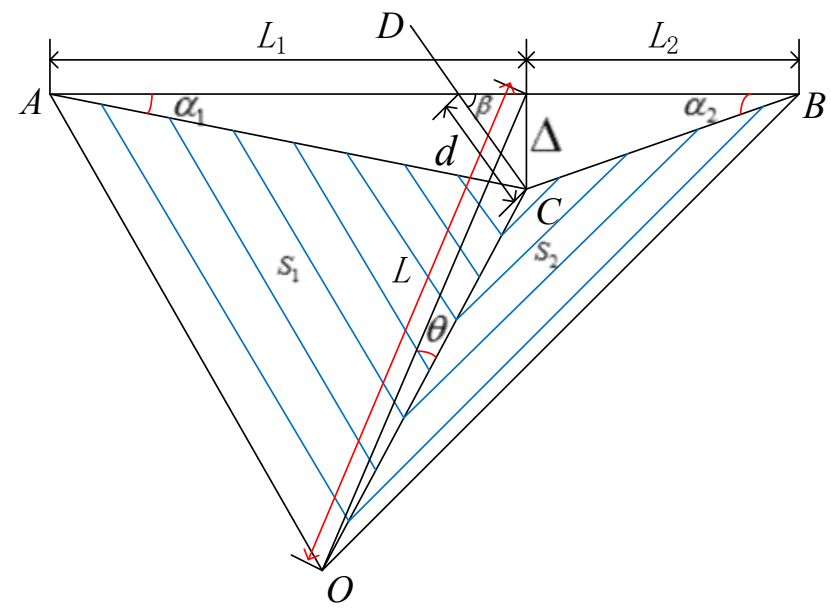

Figure 7. Deformation model of the outer shell plating after collision. 
where, $L$ is the height of the deformed side plating, $L_{1}$ is the length of the left side of the deformed side plating, $L_{2}$ is the length of the right side of the deformed side plating, line DC represents the displacement of the striking ship, $\beta$ is the collision angle between the striking ship and the struck ship, $\alpha_{1}$ is the instantaneous rotation angle of the left side in the longitudinal direction, $\alpha_{2}$ is the instantaneous rotation angle of the right side in the longitudinal direction, $\theta$ is the rotation angle of the side plating in the vertical direction, $\Delta$ is the deflection of the side plating, $F_{V}$ is the vertical force, and $F_{\text {sideplate }}$ is the collision force of the side plating. The relationship between $\Delta$ and the raked bow displacement $\delta$ 'is:

$$
\Delta=\delta^{\prime} \sin \beta
$$

$\Delta$ can also be expressed as:

$$
\Delta=L_{1} \tan \alpha_{1}=L_{2} \tan \alpha_{2}=L \tan \theta
$$

In the process of an oblique ship collision, the strain of the left part of the deformed plate can be expressed as:

$$
\varepsilon_{1}=\left(\frac{l}{\cos \alpha_{1}}-l\right) / l=\frac{1}{\cos \alpha_{1}}-1
$$

where, $l$ is the length of the plate strip and the strain rate is:

$$
\&=\frac{\sin \alpha_{1}}{\cos ^{2} \alpha_{1}} \&
$$

Similarly, for the right part of the deformed plate, the strain and the strain rate can be expressed as:

$$
\begin{gathered}
\varepsilon_{2}=\frac{1}{\cos \alpha_{2}}-1 \\
\&=\frac{\sin \alpha_{2}}{\cos ^{2} \alpha_{2}} \alpha_{2}
\end{gathered}
$$

By substituting Eq. (9) and (11) into Eq. (2), the membrane energy dissipation rate is:

$$
\mathbb{E}_{m}^{\&}=N_{0_{-} \text {sideplate }}\left(S_{1} \frac{\sin \alpha_{1}}{\cos ^{2} \alpha_{1}} \&+S_{2} \frac{\sin \alpha_{2}}{\cos ^{2} \alpha_{2}} \alpha_{2}\right)
$$

where, \&is the angular bending rate of the left part in the longitudinal direction, \& is the angular bending rate of the right part in the longitudinal direction, $S_{1}$ is the area of the left part of the deformed plate, $S_{2}$ is the area of the right part of the deformed plate, and $N_{0 \_ \text {sideplate }}$ is the unit plastic membrane force of the plate trip per length, which can be expressed as:

$$
N_{0 \_ \text {sideplate }}=\sigma_{0} t_{\text {sideplate }}
$$

where, $t_{\text {sideplate }}$ is the thickness of the side plating.

The two plastic hinge lines (lines OA and OB in Figure 7) on both sides of the deformation area mainly produce bending deformation in the longitudinal and vertical directions. The energy dissipation rate of the bending deformation in the longitudinal direction is:

$$
E_{b 1}^{\&}=M_{0} L(a \&+\&)
$$

The energy dissipation rate of the bending deformation in the vertical direction is:

$$
E_{b 2}^{\&}=M_{0}\left(L_{1}+L_{2}\right) \&
$$

where, $\varnothing$ is the angular bending rate of the deformed plate in the vertical direction and 
the total bending energy dissipation rate is:

$$
E_{b}^{\&}=E_{b 1}^{\&}+E_{b 2}^{\&}
$$

The loading rate $\&$ of the raked bow can be expressed as:

$$
\&=\frac{L_{1}}{\cos ^{2} \alpha_{1}} \&=\frac{L_{2}}{\cos ^{2} \alpha_{2}} \&=\frac{L}{\cos ^{2} \theta} \&
$$

Substituting Eq. (12), (16) and (17) into Eq. (1), the vertical force of the side plating becomes:

$$
F_{V_{-} \text {sideplate }}=\frac{E_{m}^{\&}+E_{b}^{\&}}{\&}=0.5 N_{0} L\left(\sin \alpha_{1}+\sin \alpha_{2}\right)+M_{0}\left(L_{1}+L_{2}\right) \frac{\cos ^{2} \theta}{L}+M_{0} L\left(\frac{\cos ^{2} \alpha_{1}}{L_{1}}+\frac{\cos ^{2} \alpha_{2}}{L_{2}}\right)
$$

The tangential force of the side plating is:

$$
F_{T_{-} \text {sideplate }}=\frac{0.5 N_{0} L\left(\sin \alpha_{1}+\sin \alpha_{2}\right)}{\tan \beta}+M_{0}\left(L_{1}+L_{2}\right) \frac{\cos ^{2} \theta}{L \cdot \tan \beta}+\frac{M_{0} L}{\tan \beta}\left(\frac{\cos ^{2} \alpha_{1}}{L_{1}}+\frac{\cos ^{2} \alpha_{2}}{L_{2}}\right)
$$

The collision force of the side plating during the oblique collision process is:

$$
F_{\text {sideplate }}=\frac{0.5 N_{0} L\left(\sin \alpha_{1}+\sin \alpha_{2}\right)}{\sin \beta}+M_{0}\left(L_{1}+L_{2}\right) \frac{\cos ^{2} \theta}{L \cdot \sin \beta}+\frac{M_{0} L}{\sin \beta}\left(\frac{\cos ^{2} \alpha_{1}}{L_{1}}+\frac{\cos ^{2} \alpha_{2}}{L_{2}}\right)
$$

\subsubsection{The friction and the energy dissipation due to friction}

In an oblique collision scenario, friction is mainly generated between the striking ship and the side plating of the side structure on the struck ship. The frictional force between the raked bow and the side plating during the oblique collision process is:

$$
F_{S_{-} \text {sideplate }}=\mu \cdot F_{V_{-} \text {sideplate }}=0.15 N_{0} L\left(\sin \alpha_{1}+\sin \alpha_{2}\right)+0.3 M_{0}\left(L_{1}+L_{2}\right) \frac{\cos ^{2} \theta}{L}+0.3 M_{0} L\left(\frac{\cos ^{2} \alpha_{1}}{L_{1}}+\frac{\cos ^{2} \alpha_{2}}{L_{2}}\right)(21)
$$

The energy dissipation due to friction during the oblique collision process can be expressed as:

$$
E_{f}=\int_{S}\left(F_{S_{-} \text {sideplate }}+F_{T_{-} \text {sideplate }}\right) \cdot \Delta s d S
$$

\subsection{Deformation mechanism of the web girder}

To study the deformation mechanisms of the web girder in different collision angles, numerical simulations are conducted to simulate the collision processes. Three typical oblique collision scenarios are selected, the finite element models of the raked bow impacting the web girder at 30 degrees, 45 degrees and 60 degrees are established for numerical simulations, the finite element models, the deformation models of the web girder and the deformation processes of the cross section of the web girder with oblique collision angles of 30 degrees, 45 degrees and 60 degrees are shown in Figure 8, Figure 9 and Figure 10, respectively. It can be seen from the figures that the folding length ratio of webs is similar under different oblique collision angles. Therefore, the folding length ratio of webs is assumed based on the numerical simulation results.
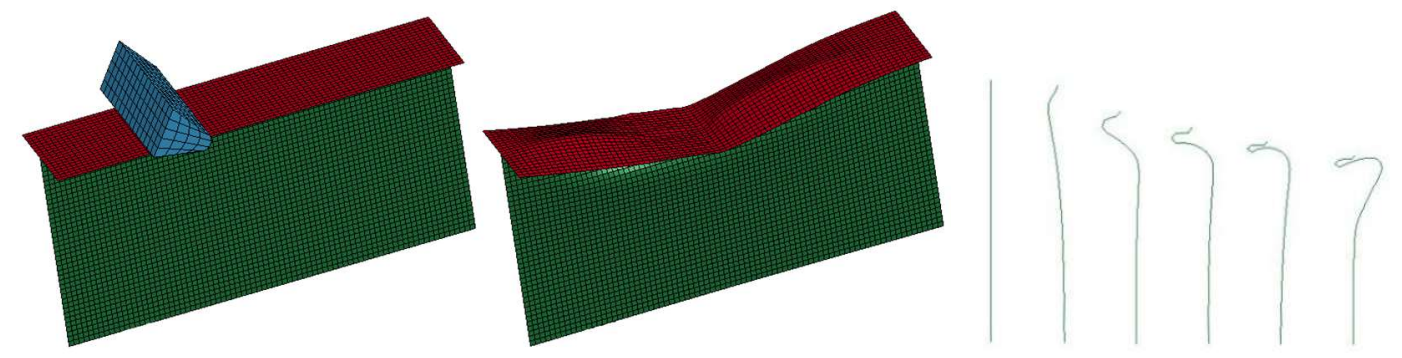

(a) The finite element model. (b) Deformation model of the web girder. (c) Deformation process of the cross section of the web girder.

Figure 8. Numerical simulation result of the web girder $\left(\beta=30^{\circ}\right)$. 

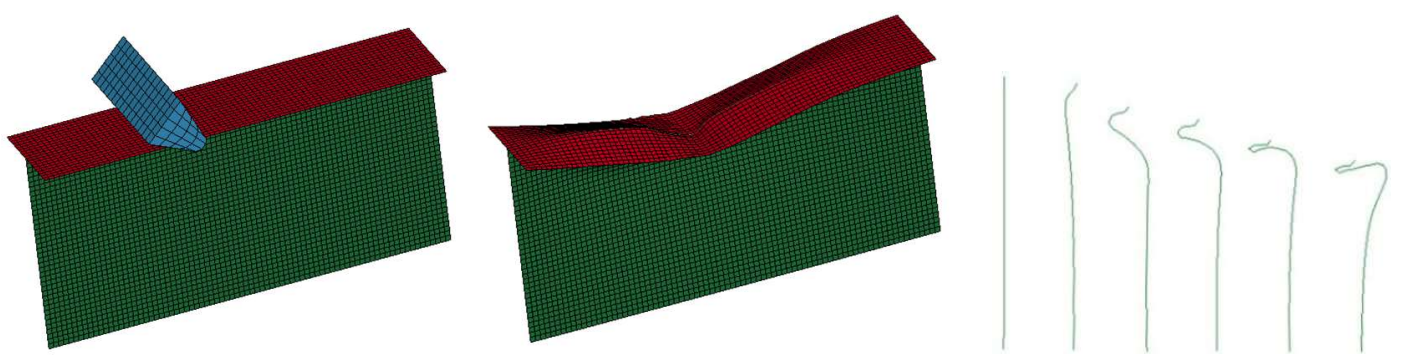

(a) The finite element model. (b) Deformation model of the web girder. (c) Deformation process of the cross section of the web girder.

Figure 9. Numerical simulation result of the web girder $\left(\beta=45^{\circ}\right)$.
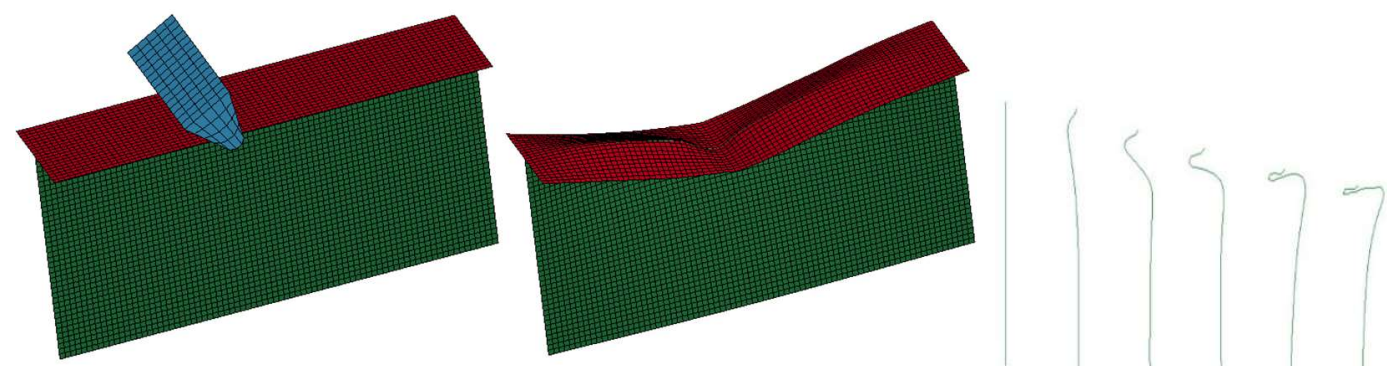

(a) The finite element model. (b) Deformation model of the web girder. (c) Deformation process of the cross section of the web girder.

Figure 10. Numerical simulation result of the web girder $\left(\beta=60^{\circ}\right)$.

The deformation characteristics of the web girders can be observed by numerical simulations. In an oblique collision scenario, the web girder is subjected to an oblique impact, so the impact force can be divided into a vertical force and a tangential force. The vertical force causes a two-dimensional folding deformation, the two-dimensional folding deformation is similar to that of the web girder in a head-on collision scenario, the tangential force has little effect on the folding deformation. According to the numerical simulation results of the web girders in collision scenarios, a theoretical model of the two-dimensional deformation of a web girder caused by a vertical force is proposed, as illustrated in Figure 11. It is assumed that the web girder is crushed according to the deformation mode shown in Figure 11, where one part has a length of $b_{1}$ and the other part has a length of $b_{2}=b-b_{1}$. As the impact depth of the case 1-6 is not large, so $b_{1}$ and $b_{2}$ don't change much. The folding deformation process of the web girder includes two folds, as shown in Figure 12. In the first fold, the middle wrinkle is two and a half times the depth of the uppermost wrinkle, which means $B C=5 / 2 A B$, and the first fold is completed when the crushing height is $7 H$. The crushing height of the second fold is $6 H$. The relationship between the crushing height $H$ in the vertical direction and the crushing distance $H$ in the oblique collision direction is:

$$
H=H \sin \beta
$$




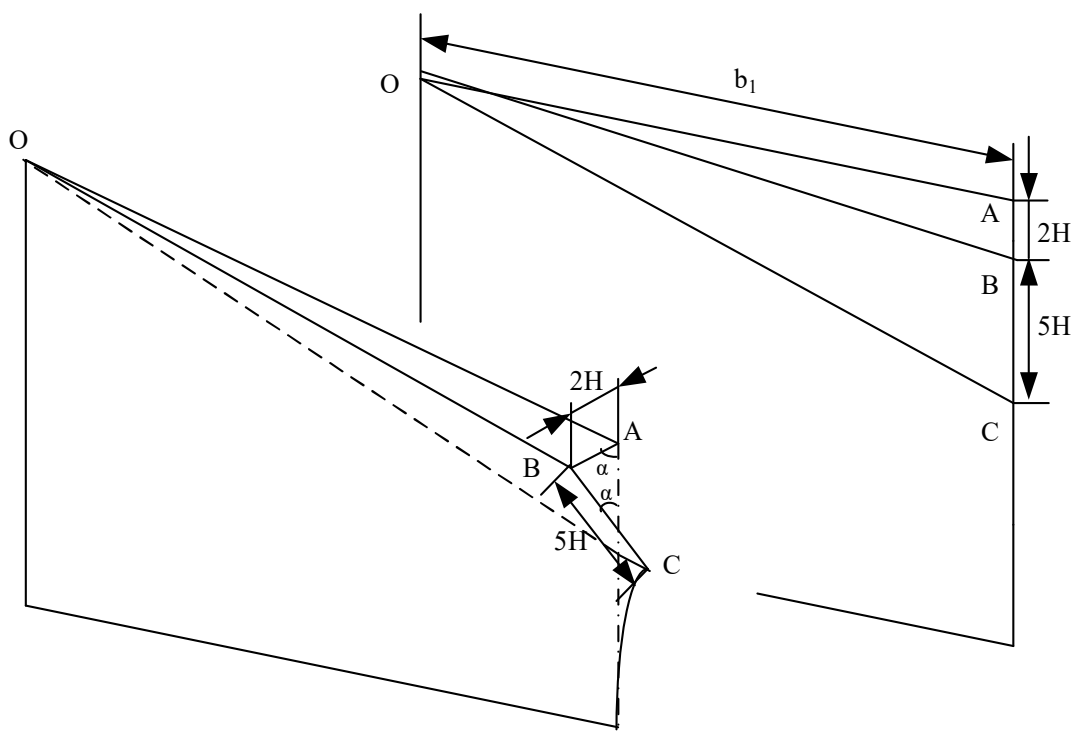

Figure 11. An analytical model of the deformed web girder after collision.

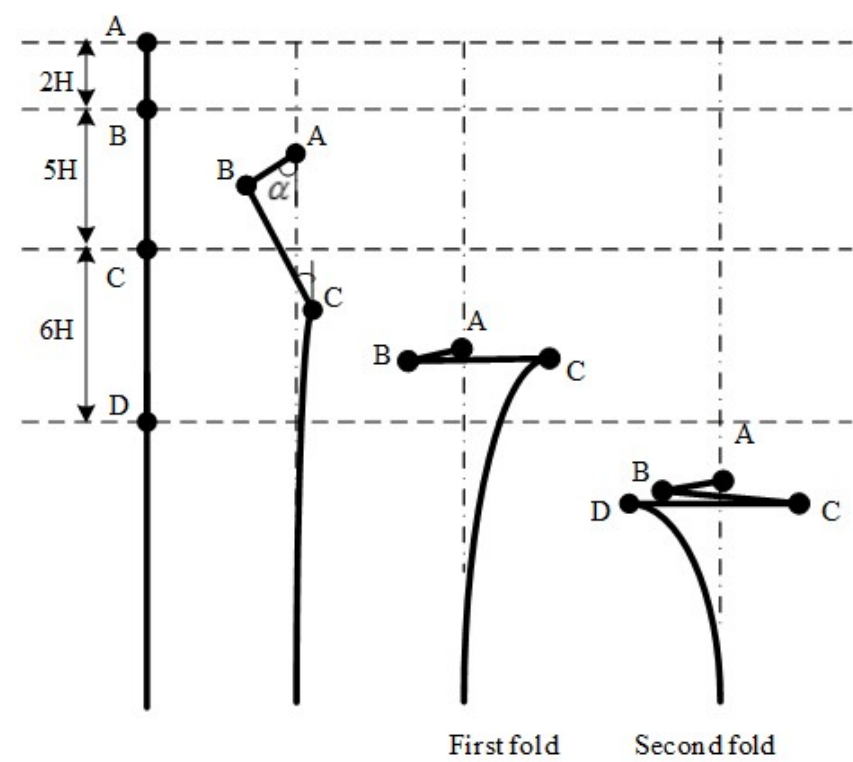

Figure 12. Progressive folding of the cross section (the black dots represent the plastic hinges).

\subsubsection{Deformation mechanism of the first fold}

During the formation of the first fold, three plastic hinge lines are formed. It is assumed that $7 H<<\left(b_{1}, b_{2}\right)$; hence, the bending energy dissipation rate can be expressed as:

$$
E_{b}^{\&}=4 M_{0}\left(b_{1}+b_{2}\right) \&
$$

where, $\dot{\alpha}$ is the angular bending rate.

The relationship between the indentation $\delta$ and the rotation angle $\alpha$ is:

$$
\delta=7 H(1-\cos \alpha)
$$

The relationship between the angular bending rate $\dot{\alpha}$ and the impact velocity $\dot{\delta}$, which can be obtained from the above formula, is expressed as:

$$
a \&=\frac{\&}{7 H \sqrt{1-\left(1-\frac{\delta}{7 H}\right)^{2}}}
$$

During the formation of the first fold, $\alpha$ increases from 0 to $\pi / 2$, and the total bending energy dissipation is: 


$$
E_{b}=2 \pi M_{0}\left(b_{1}+b_{2}\right)
$$

For the membrane energy dissipation, Simonsen ${ }^{42}$ found that when the plate is stretched along the length direction, the minimum energy dissipation can be achieved. Therefore, only the tensile stress along the length direction of the plate is considered.

The strain and strain rate of the uppermost fibre are:

$$
\begin{gathered}
\varepsilon_{O A}=\frac{1}{2}\left(\frac{\delta}{b_{1}}\right)^{2} \\
\&_{A A}=\frac{\delta}{b_{1}^{2}} \&
\end{gathered}
$$

According to the geometric relationship, the strain rates of other plastic hinge lines are:

$$
\begin{gathered}
\&_{B}=\frac{\delta}{b_{1}^{2}} \& \\
\&_{C}=0
\end{gathered}
$$

The average strain rate along the length direction over the whole height range of $7 \mathrm{H}$ can be expressed as:

$$
\underset{\text { avg }}{\&}=\frac{9}{14} \frac{\delta}{b_{1}^{2}} \&
$$

The total membrane energy dissipation rate of the web girder during the first folding process is:

$$
\mathbb{E}_{m}^{\&}=\frac{9}{2} N_{0} H\left(\frac{1}{b_{1}}+\frac{1}{b_{2}}\right) \delta \S
$$

Integrating Eq. (33) shows that when the first fold is completely formed $(\delta=7 H)$, the total membrane energy dissipation of the web girder is:

$$
E_{m}=\frac{441}{4} N_{0} H^{3}\left(\frac{1}{b_{1}}+\frac{1}{b_{2}}\right)
$$

In the oblique collision scenario, the relationship between $\delta$ and the raked bow displacement $\delta$ 'is:

$$
\delta=\delta \sin \beta
$$

Therefore, the instantaneous resistance of the web girder can be expressed as:

$$
F_{\text {girder }}\left(\delta^{\prime}\right)=\frac{E_{b}^{\&}+E_{m}^{\&}}{\delta^{\&}}=\frac{\sigma_{0} t^{2}\left(b_{1}+b_{2}\right)}{7 H^{\prime} \sin \beta \sqrt{1-\left(1-\frac{\delta^{\prime}}{7 H^{\prime}}\right)^{2}}}+\frac{9}{2} \sigma_{0} t H^{\prime} \delta^{\prime} \sin ^{2} \beta\left(\frac{1}{b_{1}}+\frac{1}{b_{2}}\right)
$$

where, $0 \leq \delta \leq 7 H^{\prime}$.

The average resistance during the deformation process of the web girder is:

$$
F_{m_{-} \text {first }}=\frac{E_{b}+E_{m}}{7 H^{\prime}}=\frac{\pi \sigma_{0} t_{\text {girder }}{ }^{2}\left(b_{1}+b_{2}\right)}{14 H^{\prime}}+\frac{63}{4} \sigma_{0} t_{\text {girder }}\left(H^{\prime}\right)^{2} \sin \beta\left(\frac{1}{b_{1}}+\frac{1}{b_{2}}\right)
$$

According to the upper bound theorem ${ }^{41}$, if the average resistance is minimized, the corresponding energy dissipation is minimized; therefore,

$$
\frac{\partial F_{m}}{\partial H^{\prime}}=0
$$

By substituting Eq. (37) into Eq. (38), $H^{\prime}$ can be expressed as:

$$
H^{\prime}=0.192\left(\frac{b_{1} b_{2} t_{\text {girder }}}{\sin \beta}\right)^{1 / 3}
$$

Thus, when the first fold is completely formed, the average resistance and instantaneous resistance of the web girder can be calculated. 


\subsubsection{Deformation mechanism of the subsequent folding}

After the completion of the first fold, as the impact depth increases, the second fold will appear. In the new deformation model, the characteristic height of the second fold and the subsequent fold is $6 \mathrm{H}$, and the analysis method of the subsequent fold is similar to the first fold. The energy dissipation is also divided into the bending energy dissipation and the membrane energy dissipation.

During the formation process of the second fold, the first fold will be further stretched and absorb some energy. Therefore, the membrane instantaneous resistance formula in the first fold formation process is still retained in the resistance formula of the second fold formation process, and the instantaneous resistance is:

$$
F_{\text {membrane }}\left(\delta^{\prime}\right)=\frac{9}{2} \sigma_{0} t H^{\prime} \sin ^{2} \beta\left(2 \delta^{\prime}-7 H^{\prime}\right)\left(\frac{1}{b_{1}}+\frac{1}{b_{2}}\right)
$$

During the formation of the second fold, the bending energy dissipation can be expressed as:

$$
E_{2 b}=\pi M_{0}\left(b_{1}+b_{2}\right)
$$

The resistance of the second fold due to bending deformation is:

$$
F_{\text {bending }}\left(\delta^{\prime}\right)=\frac{\pi \sigma_{0} t^{2}\left(b_{1}+b_{2}\right)}{24 H^{\prime} \sin \beta}
$$

Therefore, during the formation of the second fold, the instantaneous resistance of the web girder is:

$$
\begin{aligned}
F_{\text {girder }}\left(\delta^{\prime}\right) & =F_{\text {membrane }}\left(\delta^{\prime}\right)+F_{\text {bending }}\left(\delta^{\prime}\right) \\
& =\frac{9}{2} \sigma_{0} t H^{\prime} \sin ^{2} \beta\left(2 \delta^{\prime}-7 H^{\prime}\right)\left(\frac{1}{b_{1}}+\frac{1}{b_{2}}\right)+\frac{\pi \sigma_{0} t^{2}\left(b_{1}+b_{2}\right)}{24 H^{\prime} \sin \beta}
\end{aligned}
$$

The instantaneous resistance of the web girder in the subsequent folding formation process can be calculated by the same method, and the instantaneous resistance of the $n$th $(n \geq 2)$ fold can be expressed as:

$$
F_{\text {girder }}\left(\delta^{\prime}\right)=\frac{9}{2} \sigma_{0} t H^{\prime} \sin ^{2} \beta\left(n \delta^{\prime}-(n-1)(3 n+1) H^{\prime}\right)\left(\frac{1}{b_{1}}+\frac{1}{b_{2}}\right)+\frac{\pi \sigma_{0} t^{2}\left(b_{1}+b_{2}\right)}{24 H^{\prime} \sin \beta}
$$

The web girder is fitted with a flange and welded to the hull plate. The resistance of the web flange can be calculated by the beam theory adopted by Hong and Amdahl ${ }^{35}$, and the resistance of the flange plate is:

$$
F_{\text {flange }}\left(\delta^{\prime}\right)=\frac{4 \sigma_{0} a t_{f}}{b_{1}+b_{2}} \delta^{\prime} \sin \beta
$$

where, $\sigma_{0}$ is the flow stress, $a$ is the half-width of the flange plate, $t_{f}$ is the plate thickness, and $b_{1}+b_{2}$ is the length of the flange plate.

The coupling between different structures is ignored, and the total instantaneous resistance of the web girder with flange plate is:

$$
F_{\text {total }}\left(\delta^{\prime}\right)=F_{\text {girder }}\left(\delta^{\prime}\right)+F_{\text {flange }}\left(\delta^{\prime}\right)
$$

The deformation mechanism of the deck plating is similar to that of the web girder, so the resistance of the deck plating can be calculated by the above formulas.

\subsection{Deformation mechanism of the transverse frame}

When the transverse frame is subjected to a raked bow oblique impact, the major structural deformation mode is the frame's bending deformation. There is an impact angle between the raked bow and the transverse frame, and the impact force has a 
horizontal component. It is assumed that the transverse frame is crushed by a linear load of length $\mathrm{d}$, the impact force can be divided into a tangential force and a vertical force, of which the tangential force causes a horizontal displacement in the edge of the transverse frame, as shown in Figure 13, and the vertical force causes a twodimensional folding deformation, which is similar to that in Section 3.3, as shown in Figure 14.

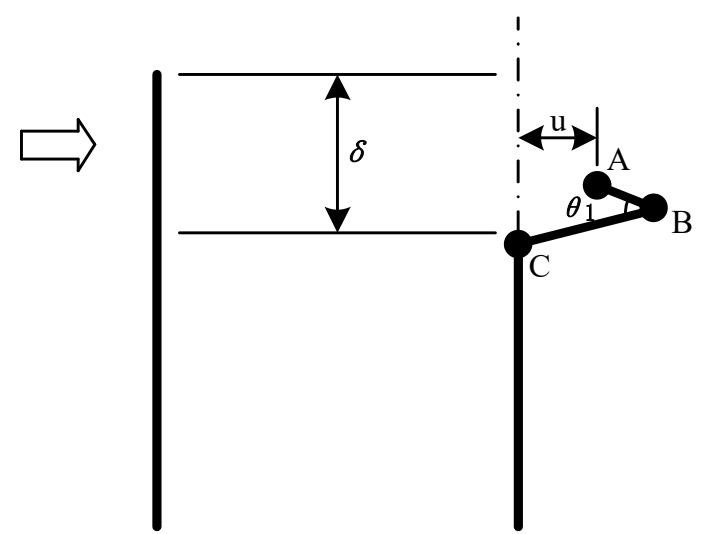

Figure 13. Cross section of the transverse frame before and after crushing ${ }^{22}$.

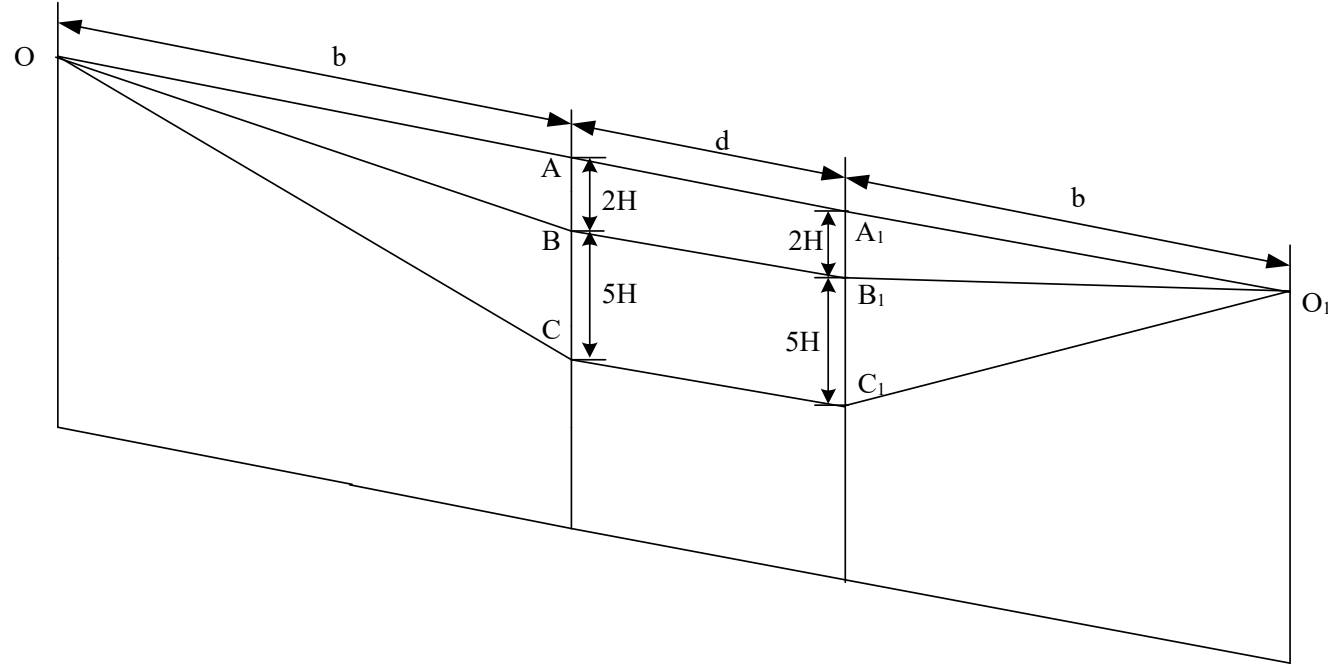

Figure 14. Deformation pattern of a crushing transverse frame.

This horizontal displacement can be calculated by the following formula ${ }^{22}$ :

$$
u=2 h \tan \theta_{1}
$$

where, $u$ is the horizontal displacement, $h$ is half of the vertical crushing distance and $\theta_{1}$ is half of the crushing wave angle.

$$
\begin{gathered}
2 h=1.0836 \delta+0.06522^{43} \\
2 \theta_{1}=0.94 \beta-0.0048 \beta^{2}{ }^{43}
\end{gathered}
$$

where, $\delta$ is the indentation and $\beta$ is the oblique collision angle.

The bending energy dissipation of the transverse frame is:

$$
E_{b}=2 \pi M_{0}(d+2 b)
$$

When the indentation $\delta$ is $7 H$, the membrane energy dissipation of the transverse frame is:

$$
E_{m}=\frac{441}{4} N_{0} \delta^{3}\left(\frac{2}{b}+\frac{d}{b^{2}}\right)
$$

The total energy dissipation is: 


$$
E_{t}=E_{b}+E_{m}=2 \pi M_{0}(d+2 b)+\frac{441}{4} N_{0} \delta^{3}\left(\frac{2}{b}+\frac{d}{b^{2}}\right)
$$

According to the upper bound theorem ${ }^{41}$, if the energy dissipation is minimized, then

$$
\frac{\partial E_{t}}{\partial b}=0
$$

By substituting Eq. (52) into Eq. (53), $d$ can be expressed as:

$$
d=\frac{2 \pi t}{441 \delta^{3}} b^{3}-b
$$

The total energy dissipation of the transverse frame can also be expressed as:

$$
E_{t}=F_{T_{-} \text {frame }} \cdot u+F_{V_{-} \text {frame }} \cdot \delta
$$

The relationship between the tangential force $F_{T_{-} \text {frame }}$ and the vertical force $F_{V_{-} \text {frame }}$ is:

$$
F_{V_{-} \text {frame }}=F_{T_{-} \text {frame }} \tan \beta
$$

By combining Eq. (47) through Eq. (56), the tangential force $F_{T_{-} \text {frame }}$ and the vertical force $F_{V_{-} \text {frame }}$ can be obtained as:

$$
\begin{gathered}
F_{T_{-} \text {frame }}=\frac{E_{t}}{u+\delta \cdot \tan \beta}=\frac{\frac{\pi \sigma_{0} t^{2}}{2}\left(\frac{2 \pi t}{441\left(\delta^{\prime} \sin \beta\right)^{3}} b^{3}+b\right)+\frac{441}{4} \cdot \sigma_{0} t\left(\delta^{\prime} \sin \beta\right)^{3} \cdot\left(\frac{2 \pi t b}{441\left(\delta^{\prime} \sin \beta\right)^{3}}+\frac{1}{b}\right)}{\left(1.0836 \delta^{\prime} \sin \beta+0.0652\right) \cdot \tan \left(0.47 \beta-0.0024 \beta^{2}\right)+\delta^{\prime} \cdot \sin \beta \cdot \tan \beta} \\
F_{V_{-} \text {frame }}=F_{H_{-} \text {frame }} \tan \beta=\frac{\frac{\pi \sigma_{0} t^{2}}{2}\left(\frac{2 \pi t}{441\left(\delta^{\prime} \sin \beta\right)^{3}} b^{3}+b\right)+\frac{441}{4} \cdot \sigma_{0} t\left(\delta^{\prime} \sin \beta\right)^{3} \cdot\left(\frac{2 \pi t b}{441\left(\delta^{\prime} \sin \beta\right)^{3}}+\frac{1}{b}\right)}{\left(1.0836 \delta^{\prime} \sin \beta+0.0652\right) \cdot \tan \left(0.47 \beta-0.0024 \beta^{2}\right)+\delta^{\prime} \cdot \sin \beta \cdot \tan \beta} \cdot \tan \beta
\end{gathered}
$$

\subsection{Analytical method prediction procedure}

The structural response prediction of ship side structure subjected to a raked bow oblique collision by analytical method can be divided into the following steps. First, define the collision scenarios and select the impact positions. Then, identify the damage structures and their parameters during collision process. In a ship collision accident, the failure patterns have clear boundaries between the deformed area and the undeformed area. It is assumed that the deformation area is determined by the nearest undamaged components, which limit the area of the deformed structures. Next, when the collision scenarios and the outlines of the striking ship's raked bow are determined, combining the outlines of the striking ship's raked bow and the layout of the struck ship's side structure, the collision process in a plane figure can be simulated, so the structural components involved in collision process can be determined. Finally, the resistance of structural components participate in withstanding the collision can be obtained by the above formulas, Figure 15 shows the flow chart for predicting the resistance of the struck ship. 


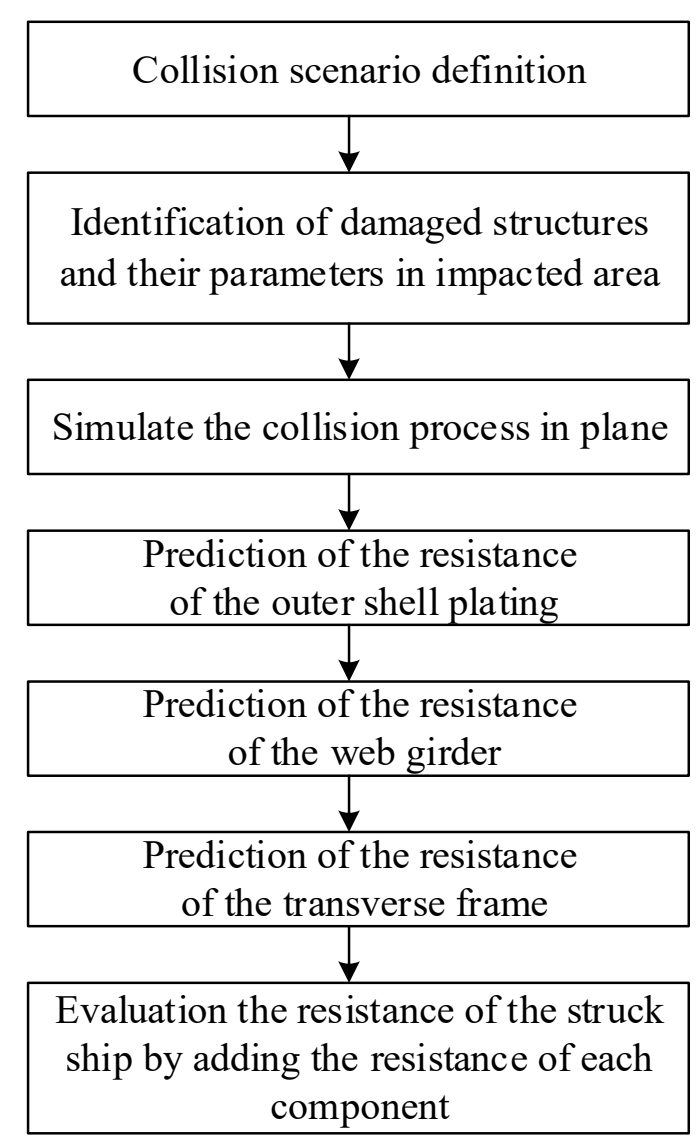

Figure 15. Flowchart of calculating resistance of the struck ship.

\section{Validations and discussions}

The nonlinear finite element software LS_DYNA is used for numerical simulations of the six oblique collision cases proposed in Section 2.2, and the detailed information of the finite element models is given in Section 2.1. The energy absorption and resistance curves of the struck ship obtained by numerical simulation are compared with the results calculated by the proposed analytical method, as shown in Figures 16-21. The displacement in Figures 16-21 is the indentation of the striking ship in collision direction.

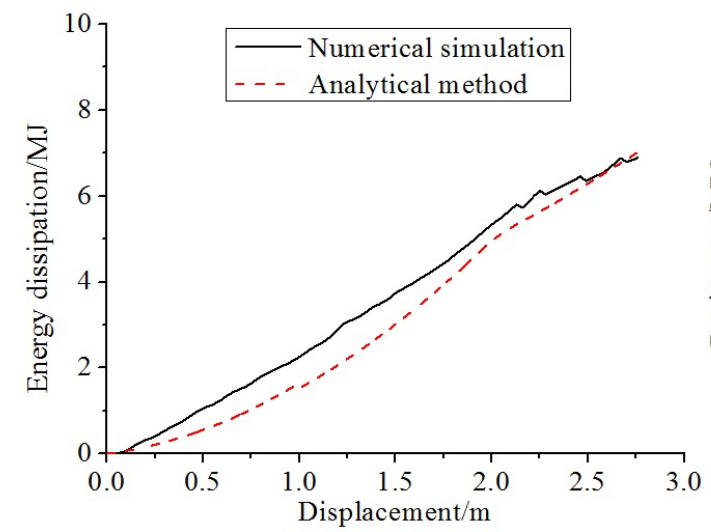

(a)

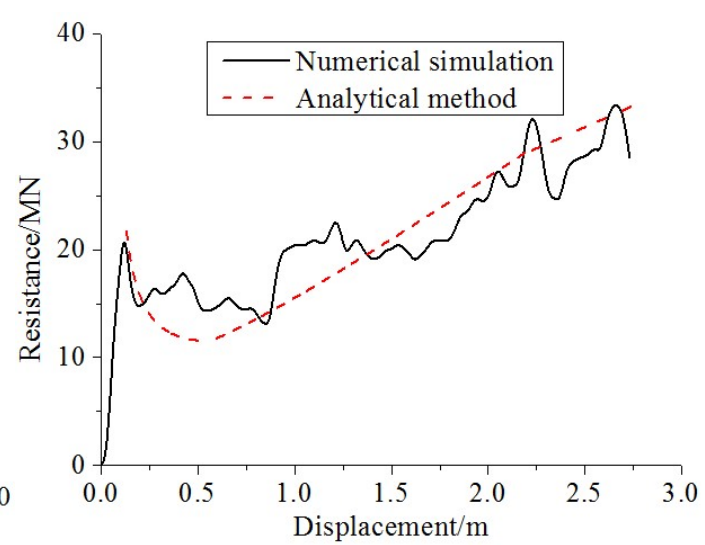

(b)

Figure 16. Comparison of the numerical simulation and analytical method results for case $1\left(\beta=30^{\circ}\right)$ :

(a) energy dissipation and (b) resistance force. 


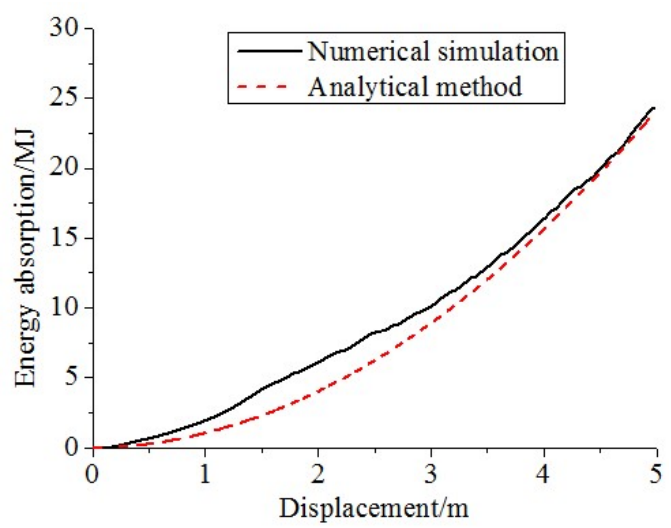

(a)

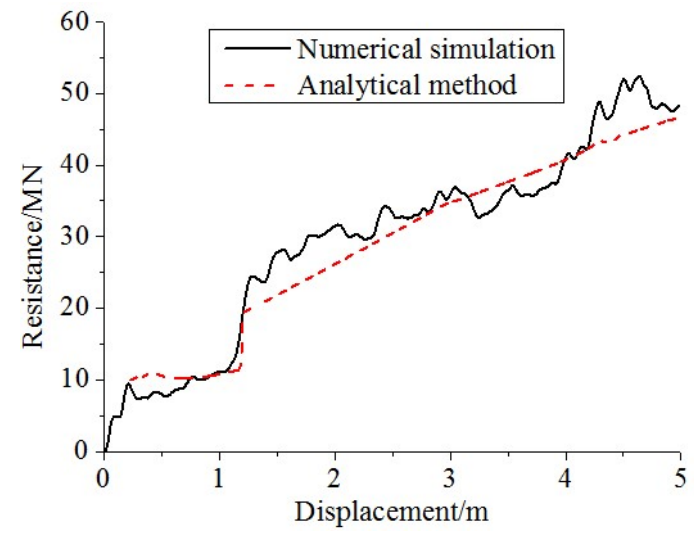

(b)

Figure 17. Comparison of the numerical simulation and analytical method results for case $2\left(\beta=45^{\circ}\right)$ :

(a) energy dissipation and (b) resistance force.

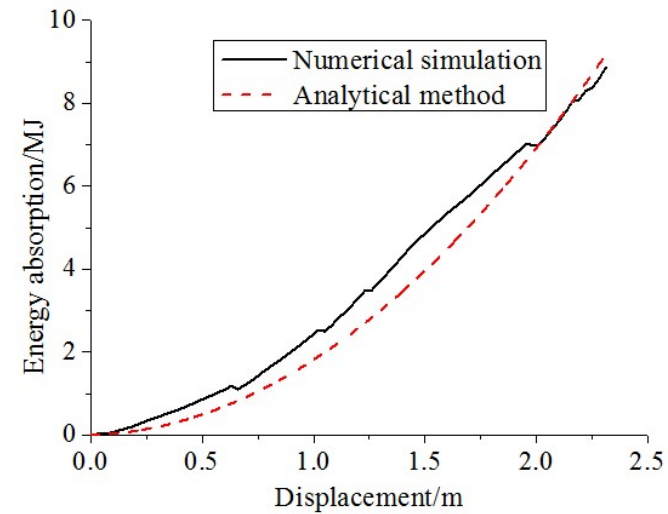

(a)

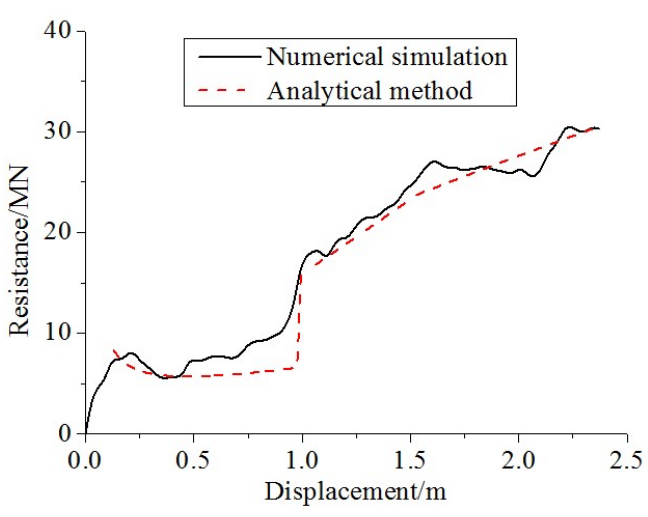

(b)

Figure 18. Comparison of the numerical simulation and analytical method for case $3\left(\beta=60^{\circ}\right)$ :

(a) energy dissipation and (b) resistance force.

In case 1, the main components, including the outer shell plating, the deck plating and the transverse frame take part in withstanding the collision in the initial stage. As the impact indentation increases, the energy absorbed by the struck ship increases, and the resistance of the side structure also increases. When the impact indentation reaches approximately $1.0 \mathrm{~m}$, the transverse frame begins to participate in the resistance, as shown in Figure 16 (b). In case 2, the outer shell plating, also as the main component, takes part in withstanding the collision in the initial stage, and the deck plating is considered when the impact indentation reaches approximately $1.1 \mathrm{~m}$. The transverse frames begin to withstand the collision when the impact indentation reaches approximately $3.7 \mathrm{~m}$, as shown in Figure 17 (b). In case 3, the outer shell plating mainly takes part in withstanding the collision in the initial stage. As the impact indentation increases, the energy absorbed by the struck ship increases, and the resistance of the side structure also exhibits an increasing trend. When the impact indentation reaches approximately $0.9 \mathrm{~m}$, the deck plating begins to participate in the resistance, and the resistance of the ship side structure increases significantly, as shown in Figure 18 (b). These characteristics are also taken into account in the analytical method. 


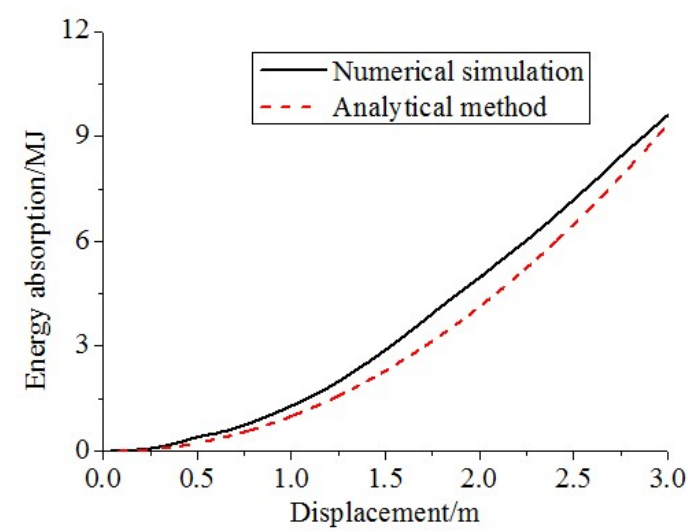

(a)

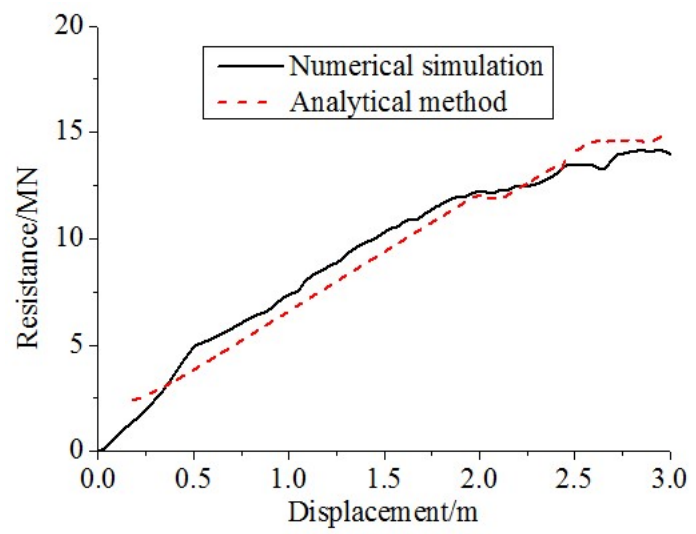

(b)

Figure 19. Comparison of the numerical simulation and analytical method results for case $4\left(\beta=30^{\circ}\right)$ :

(a) energy dissipation and (b) resistance force.

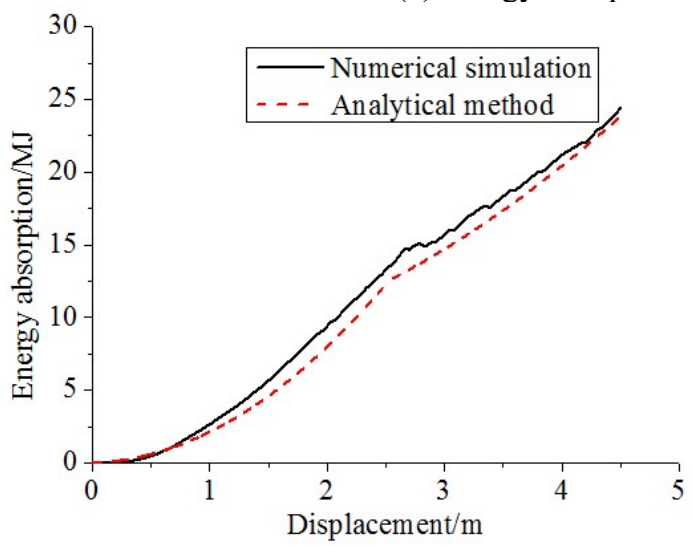

(a)

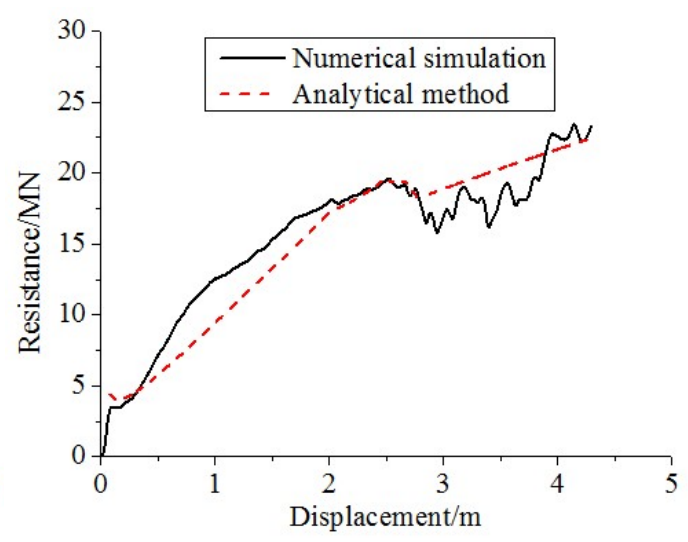

(b)

Figure 20. Comparison of the numerical simulation and analytical method results for case $5\left(\beta=45^{\circ}\right)$ :

(a) energy dissipation and (b) resistance force.

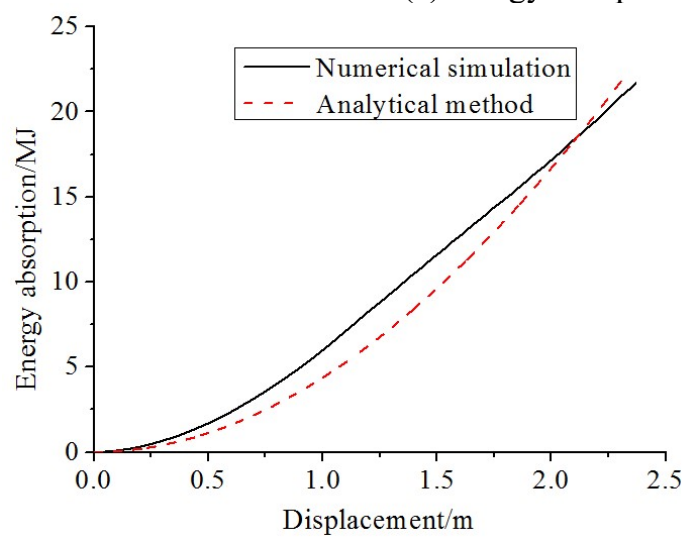

(a)

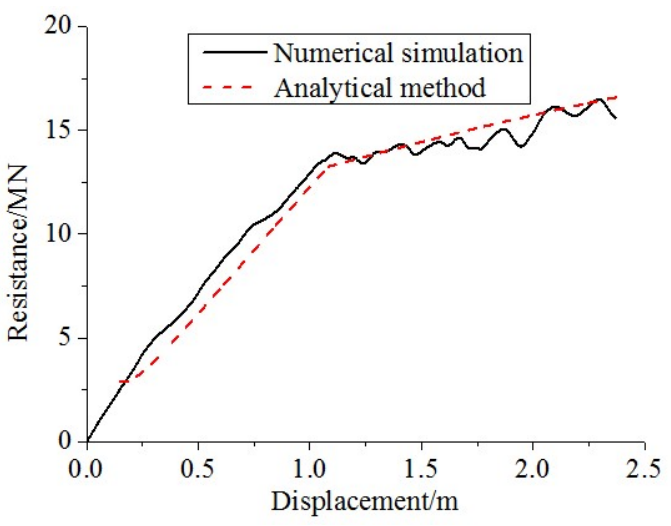

(b)

Figure 21. Comparison of the numerical simulation and analytical method results for case $6\left(\beta=60^{\circ}\right)$ : (a) energy dissipation and (b) resistance force.

In case 4, the outer shell plating, as the main component, takes part in withstanding the collision in the initial stage. When the impact indentation reaches approximately $0.5 \mathrm{~m}$, the transverse frame begins to participate in withstanding the collision. As the impact indentation increases, the energy absorbed by the struck ship increases, and the resistance of the side structure also exhibits an increasing trend, as shown in Figure 19. In case 5, the outer shell plating, also as the main component, takes part in withstanding the collision in the initial stage. When the impact indentation reaches approximately 0.3 $\mathrm{m}$, the transverse frame participates in withstanding the collision. As the collision 
process continues, the energy absorbed by the struck ship increases. When the impact indentation reaches approximately $2.75 \mathrm{~m}$, the transverse frame is crushed, and the resistance of the ship side structure decreases. Later, another transverse frame begins to participate in withstanding the collision, and the resistance increases, as shown in Figure 20. These characteristics are also taken into account in the analytical method. In case 6 , the outer shell plating, as the main component, takes part in withstanding the collision in the initial stage. When the impact indentation reaches approximately $1.0 \mathrm{~m}$, the transverse frame begins to participate in withstanding the collision. As the impact indentation increases, the energy absorbed by the struck ship increases, and the resistance of the side structure also exhibits an increasing trend, as shown in Figure 21.

Table 4. Comparison of the energy dissipation results (units: MJ).

\begin{tabular}{lccc}
\hline Case & Numerical simulation & Analytical method & Error \\
\hline Case 1 & 6.89 & 7.15 & $3.77 \%$ \\
Case 2 & 25.3 & 23.9 & $-5.53 \%$ \\
Case 3 & 8.86 & 9.41 & $6.21 \%$ \\
Case 4 & 9.51 & 9.89 & $3.99 \%$ \\
Case 5 & 24.4 & 23.8 & $-2.46 \%$ \\
Case 6 & 21.7 & 23.4 & $7.83 \%$ \\
\hline
\end{tabular}

Table 5. Comparison of the average resistance results (units: MN).

\begin{tabular}{lccc}
\hline Case & Numerical simulation & Analytical method & Error \\
\hline Case 1 & 20.9 & 21.9 & $4.78 \%$ \\
Case 2 & 30.6 & 29.4 & $-3.92 \%$ \\
Case 3 & 17.9 & 17.4 & $-2.79 \%$ \\
Case 4 & 9.13 & 9.42 & $3.18 \%$ \\
Case 5 & 15.3 & 16.9 & $10.5 \%$ \\
Case 6 & 11.3 & 12.1 & $7.08 \%$ \\
\hline
\end{tabular}

Table 6. The main structural components participating in the oblique collision process.

\begin{tabular}{lc}
\hline Case & Main participating structural components \\
\hline Case 1 & Outer shell plating, deck plating, transverse frame \\
Case 2 & Outer shell plating, deck plating, transverse frame \\
Case 3 & Outer shell plating, deck plating \\
Case 4 & Outer shell plating, transverse frame \\
Case 5 & Outer shell plating, transverse frame \\
Case 6 & Outer shell plating, transverse frame \\
\hline
\end{tabular}

Table 4 and Table 5 show comparisons of the energy dissipation and average resistance results, respectively, and Table 6 lists the main components that participate in withstanding the collision during the oblique collision process. The figures and tables show that the results obtained by the analytical method and numerical simulations are in good agreement, which also validates the accuracy of the analytical method proposed in this paper; therefore, the proposed analytical method can be used to evaluate the crashworthiness of the ship side structure in oblique ship collisions.

\section{Conclusions}

In this paper, the deformation damage mechanism of a ship side structure subjected to a raked bow oblique collision is investigated, and a simplified analytical method is proposed for predicting the structural response of a ship side structure in raked bow oblique collision scenarios. The new analytical method includes the deformation 
mechanism of the side plating, the web girder and the transverse frame, which can capture the important deformation features of the models. By applying a simplified analytical method based on the upper bound theorem, the energy dissipation and resistance formulas for the structural components can be derived. Six oblique collision scenarios are defined, assuming that there is no coupling effect between the structural components, the energy dissipation and the resistance of the individual components can be obtained, and then the overall crashworthiness of the struck ship side structure can be evaluated. The finite element software LS_DYNA is used in this study for numerical simulations. A comparison of the analytical calculation results and the numerical simulation results shows that the results are in good agreement, which validates the accuracy of the analytical method proposed in this paper; therefore, the proposed analytical method can be a useful tool to make a quick evaluation of the structural crashworthiness of ship side structures in oblique collision scenarios.

\section{Appendix}

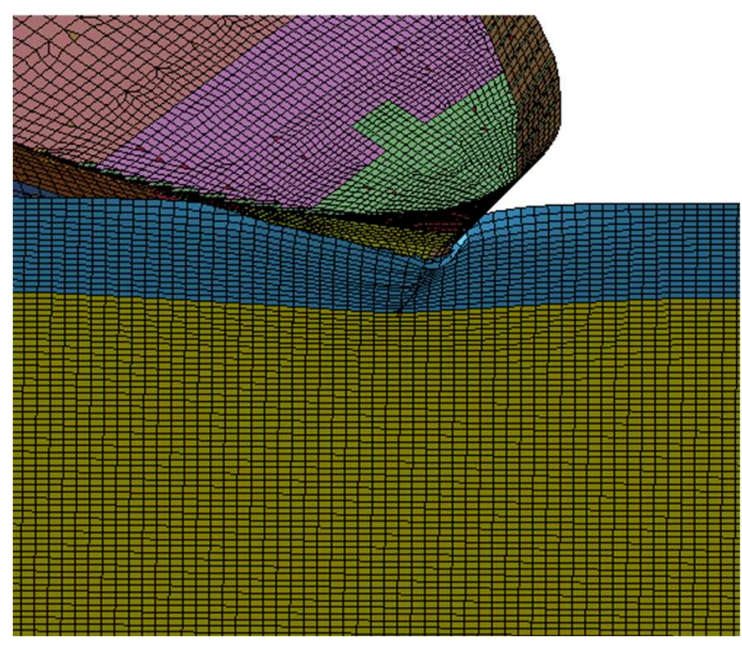

Figure 1. The deformation mode of the side plating.

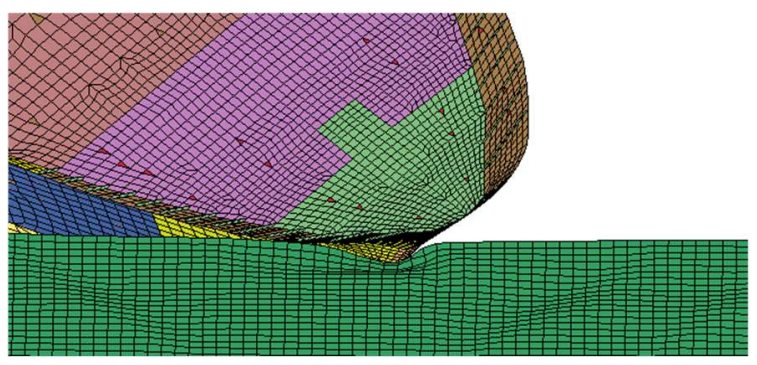

Figure 2. The deformation mode of the web girder. 


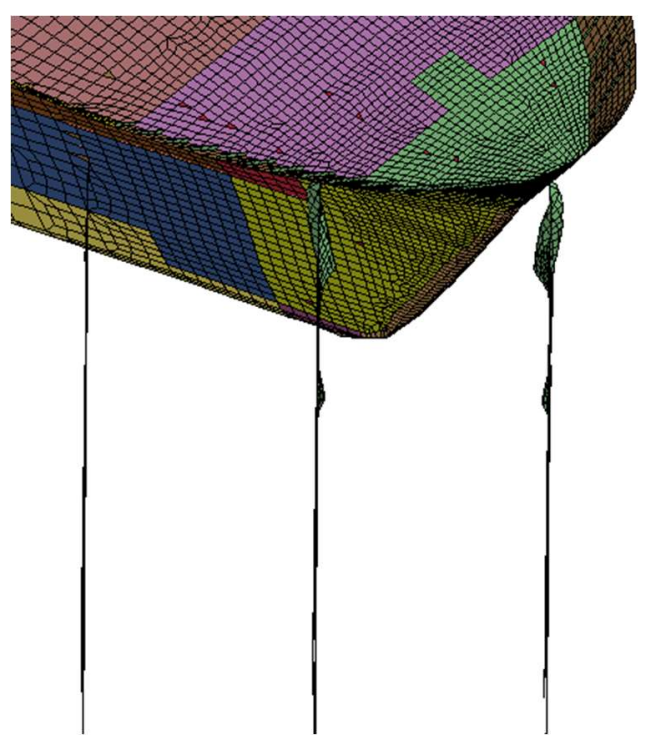

Figure 3. The deformation mode of the transverse frame.

\section{References}

1. Yamada Y, Tozawa S, Arima T. Effects of highly ductile steel on the crashworthiness of hull structure in oblique collision. In: Proceedings of the 7th International Conference on Collision and Grounding of Ships and Offshore Structures, 2016; 217-223.

2. Minorsky VU. An analysis of ship collisions with reference to protection of nuclear power plants. J Ship Res 1958;3(2):1-4.

3. Woisin G. Design against collision. Schiff \& Hafen 1979;31(2):1059-1069.

4. Vaughan H. Bending and tearing of plate with application to ship bottom damage. Naval Architect 1978;3:97-99.

5. Pedersen PT, Zhang SM. Absorbed energy in ship collisions and grounding - Revising Minarsky's empirical method. J Ship Res 1998;44(2):140-154.

6. Zhang S, Pedersen PT. A method for ship collision damage and energy absorption analysis and its validation. Ships Offshore Struct 2016;12(sup1):1-10.

7. Pedersen PT, Valsgård S, Olsen D, Spangenberg S. Ship impacts: Bow collisions. Int J Impact Eng 1993;13(2):163-187.

8. Akita Y, Ando N, Fujita Y, Kitamura K. Studies on collision-protective structures in nuclear powered ships. Nucl Eng Des 1972;19(2):365-401.

9. Amdahl J. Energy absorption in ship-platform impacts. Impact Loads 1983.

10. Paik JK. Cutting of a longitudinally stiffened plate by a wedge. Wedges 1994;38(4):340-348.

11. Wang G, Arita K, Liu D. Behavior of a double hull in a variety of stranding or collision scenarios. Mar Struct 2000;13(3):147-187.

12. Tabri K, Broekhuijsen J, Matusiak J, Varsta P. Analytical modelling of ship collision based on fullscale experiments. Mar Struct 2009;22(1):42-61.

13. Endo H, Yamada Y, Ou K, Suzuki K. Model test on the collapse strength of the buffer bow structures. Mar Struct 2002;15(4 - 5):365-381.

14. Villavicencio R, Liu B, Soares CG. Experimental and numerical analysis of a tanker side panel laterally punched by a knife edge indenter. Mar Struct 2014;37(JUL.):173-202.

15. Liu B, Soares CG. Effect of strain rate on dynamic responses of laterally impacted steel plates. Int 
J Mech Sci 2019;160:307-317.

16. Calle, M. AG, Oshiro, R. E, Alves, M. Ship collision and grounding: Scaled experiments and numerical analysis. Int J Impact Eng 2017.

17. Calle MAG, Oshiro RE, Korgesaar M, Alves M, Kujala P. Combined strain rate, mesh size and calibration test influence on structural failure: Miniature ship grounding test. Ocean Eng 2019;173(FEB.1):215-226.

18. Haris S, Amdahl J. Analysis of ship - ship collision damage accounting for bow and side deformation interaction. Mar Struct 2013;32(7):18-48.

19. Yamada Y, Endo H. Experimental and Numerical Study on the Collapse Strength of the Bulbous Bow Structure in Oblique Collision. Mar Technol 2008;45(1):42-53.

20. Yu Z, Hu Z, Amdahl J, Liu Y. Investigation on structural performance predictions of double-bottom tankers during shoal grounding accidents. Mar Struct 2013;33(10):188-213.

21. Hu Z, Amdahl J, Lin H. Verification of a simplified analytical method for predictions of ship groundings over large contact surfaces by numerical simulations. Mar Struct 2011;24(4):436-458.

22. Hong L, Amdahl J. Rapid assessment of ship grounding over large contact surfaces. Ships Offshore Struct 2012;7(1):5-19.

23. Ringsberg JW, Hogström P. A methodology for comparison and assessment of three crashworthy side-shell structures: The X-core, Y-core and corrugation panel structures. In: Proceedings of the 6th International Conference on Collision and Grounding of Ships and Offshore Structures, 2013; 323-330.

24. Ringsberg JW, Amdahl J, Chen BQ, Cho S, Ehlers S, Hu Z, Kubiczek JM, Kõrgesaar M, Liu B, Marinatos JN and others. MARSTRUCT benchmark study on nonlinear FE simulation of an experiment of an indenter impact with a ship side-shell structure. Mar Struct 2018;59(may):142-157.

25. Kitamura O. FEM approach to the simulation of collision and grounding damage. Mar Struct 2002;15(4):403-428.

26. Alsos HS, Amdahl J, Hopperstad OS. On the resistance to penetration of stiffened plates, Part II: Numerical analysis. Int J Impact Eng 2009;36(7):875-887.

27. Ehlers S, Tabri K, Romanoff J, Varsta P. Numerical and experimental investigation on the collision resistance of the X-core structure. Ships Offshore Struct 2012;7(1):21-29.

28. Simonsen BC, Törnqvist R. Experimental and numerical modelling of ductile crack propagation in large-scale shell structures. Mar Struct 2004;17(1):1-27.

29. Liu K, Wang Z, Tang W, Zhang Y, Wang G. Experimental and numerical analysis of laterally impacted stiffened plates considering the effect of strain rate. Ocean Eng 2015;99:44-54.

30. Zhu L, Liang Q, Chen M, Zhang S. On the fluid-structure response of elastic-plastic ship sides subjected to impact loads. Mar Struct 2020;70(Mar.):102691-102698.

31. Alexander JM. An approximate analysis of the collapse of thin cylindrical shells under axial loading. Q J Mech Appl Math 1960;13(1):10-15.

32. Wang G. Wang G. Structural analysis of ships' collision and grounding. University of Tokyo, 1995.

33. Simonsen BC. Ship grounding on rock-I. Theory. Mar Struct 1997;10(7):519-562.

34. Zhang S. Plate tearing and bottom damage in ship grounding. Mar Struct 2002;15(2):101-117.

35. Hong L, Amdahl J. Crushing resistance of web girders in ship collision and grounding. Mar Struct 2008;21(4):374-401.

36. Liu B, Soares CG. Analytical method to determine the crushing behaviour of girders with stiffened web. Int J Impact Eng 2016;93:49-61.

37. Yu Z, Hu Z, Wang G. Plastic mechanism analysis of structural performances for stiffeners on 
bottom longitudinal web girders during a shoal grounding accident. Mar Struct 2015;40:134-158.

38. Liu B. Analytical method to assess double-hull ship structures subjected to bulbous bow collision. Ocean Eng 2017;142(sep.15):27-38.

39. Zhang S, Pedersen PT, Villavicencio R. Probability and mechanics of ship collision and grounding. Butterworth-Heinemann, 2019.

40. Jones, N. Review of the plastic behavior of beams and plates. International Shipbuilding Progress 1972;19: 313-27.

41. Søreide, T.H. Ultimate Load Analysis of Marine Structures. Tapir, Trondheim, 1981.

42. Simonsen BC, Hasan O. Experiments and theory on deck and girder crushing. Thin Wall Struct 1999;34(3):195-216.

43. Hong L, Amdahl J. Plastic mechanism analysis of the resistance of ship longitudinal girders in grounding and collision. Ships Offshore Struct 2008;3(3):159-171. 